\title{
JUROR PERCEPTIONS IN SEXUAL \\ ORIENTATION-BASED \\ HATE CRIMES
}

by

ERIN L. GORTER

\section{A DISSERTATION}

Submitted in partial fulfillment of the requirements for the degree of Doctor of Philosophy in the Department of Psychology

in the Graduate School of

The University of Alabama

TUSCALOOSA, ALABAMA 
Copyright Erin L. Gorter 2010

ALL RIGHTS RESERVED 


\begin{abstract}
The present study sought to investigate how victim sexual orientation and homonegativity influence the relationship between severity of crime and assignment of punishment to the perpetrator of a sexual orientation-based (SO) hate crime. These differences were examined across three levels of hate crime: misdemeanor assault, felony assault, and attempted murder. In addition, a secondary focus of this study was to examine whether jurors' perceptions of perpetrator and victim blame varied based on the severity of the crime and the victim's sexual orientation. Previous literature has shown that juror sexual prejudice (i.e., homonegativity) influences jurors' perceptions and decision-making processes in similar contexts; therefore, the researchers explored whether homonegativity moderates each of the proposed relations.
\end{abstract}

A total of 238 participants were recruited from jury pools in four counties located in the state of Alabama. Participants completed a series of questionnaires related to a trial vignette, which depicted one of three varying levels of an SO hate crime. Results showed a significant main effect of the severity of crime on sentencing recommendation with the length of punishment increasing with the severity of the crime. No significant main effect of victim sexual orientation and no significant interaction between severity of crime and homonegativity were found on sentencing recommendation. It was also found that more blame was assigned to the perpetrator when the victim was heterosexual and significantly lower levels of victim blame were found when the crime was a misdemeanor assault as opposed to a felony assault or 
attempted murder. However, both of these relations became non-significant when homonegativity was entered into the model indicating the variables were unable to explain a unique amount of variance in the perceptions of blame. Finally, it was found that participants with higher levels of homonegativity assigned higher amounts of blame to the victim (regardless of the victim's sexual orientation).

Theoretical and practical implications of these results are discussed. The results suggest there are some factors which may unduly influence jury members in SO hate crimes and could lead to homosexual victims experiencing additional negative consequences during these trials. The current study also demonstrates the need for additional research on jury decision-making in SO hate crimes to ensure that victims of these crimes are being treated fairly within the justice system. 


\section{LIST OF ABBREVIATIONS AND SYMBOLS}

$\begin{array}{ll}\text { AFS } & \text { Attribution of Fault Scale } \\ \text { ANCOVA } & \text { Analysis of Covariance } \\ \text { ANOVA } & \text { Analysis of Variance } \\ \beta & \text { Beta: standardized regression coefficient } \\ \text { DAT } & \text { Defensive Attribution Theory } \\ \text { F } & \text { Test statistic } \\ \text { LGB(T) } & \text { Lesbian, Gay, Bisexual (or Transgender) } \\ \text { MHS } & \text { Modern Homonegativity Scale } \\ \text { PPBS } & \text { Perceptions of Perpetrator Blame Scale } \\ \text { SIT } & \text { Social Identity Theory } \\ s^{2} & \text { Perceptions of Victim Blame Scale } \\ n & \text { Total number in a sample } \\ & \end{array}$


SO

SRF

$\bar{X}$

Sexual Orientation-Based

Sentencing Recommendation Form

Mean: the sum of a set of measurements divided by the number of

measurements in the set 


\section{ACKNOWLEDGMENTS}

It has been a long and winding road...but the end is in sight and there are many people I'd like to recognize who have supported me throughout this project and my graduate school career. First, and foremost, my deepest gratitude goes to my parents for the endless emotional support and encouragement they have provided throughout my life. Without their guidance, willingness to allow me to follow my own path, and ability to make me laugh even during the most difficult times, I'm not sure I would have made it through the challenges. Similarly, my entire extended family has been a source of joy and motivation for me, to which I'm appreciative.

One of my largest acknowledgments must be paid to Dr. Karen Salekin. Over the past five years you have been my mentor, my teacher, and have become a friend. There aren't enough words to express how you've shaped my life and my professional development. From learning the importance of being concise and having good flow in my writing style, to learning how to balance my professional and personal life, there was rarely an occasion when I walked away from a conversation without having learned something. You challenged me to become more than just average and your humor kept me sane during the struggles of graduate school. I look forward to continuing to foster a professional and personal relationship with you regardless of where my next path leads.

Much of the current project could not have been undertaken without the support and guidance of Mr. Joel Sogol. It was truly touching how willing you were to join this committee 
and introduce me throughout the legal community, providing me with the connections that were necessary to gain access to the jury pools utilized. This went above and beyond any expectations I had for any committee member, especially one who was unfamiliar with me prior to this project. Without your legal knowledge and guidance, this project would have been much weaker and may not have been possible in its current format. I thank you from the bottom of my heart!

I would also like to thank Dr. Stanley Brodsky for sharing his insights on jury research and his guidance on how to become an ethical forensic psychologist. Your anecdotes and smiles have always brought me joy and have contributed to my belief that the training I've received in this graduate program has been invaluable. Thank you for always being someone who strives to make each of the psych/law students the best we can be. In addition, I want to express my appreciation for Dr. Beverly Thorn. You started out by guiding me into this training program and being present and approachable during the initial transition into graduate school (which, let's face it, is often rough). To have you as part of this committee and guiding me at the end of this program seems very fitting. I thank you for the insights you provided me in development of the current study and your support in my continuing endeavors.

To Dr. Mark Klinger, I thank you for your contributions while serving on this committee. You helped me to develop a clearer understanding of how to conceptualize my hypotheses and recognize the appropriate statistical approaches to examine the results. Your patience and clarity during these encounters assisted in providing me with more confidence about the outcome of the study and the development of my research skills. Similarly, I have to recognize Dr. Jamie Decoster for his countless efforts in guiding me during my statistical "breakdowns." You may 
never know how appreciative those of us who are not statistically minded are for your willingness to share your knowledge and teach statistics in terms that are easy to understand.

I would be remiss not to recognize my fellow lab members and friends, Bridget Doane, Emily Wakeman, Krystal Hedge, and Debra Chen. Bridget and Emily, you have been wonderful guides and emotional supports through the trials and tribulations. I could say much more, but I believe you know how I feel already. Krystal and Debra, thank you for the time and effort you spent in helping to review this document and providing valuable suggestions which won't be forgotten. We may have only gotten a short amount of time together at UA, but I hope that I can continue to provide some guidance to you even from afar.

Financial support for this project was provided by the American Psychological Association of Graduate Students LGBT Dissertation Scholarship and the American Academy of Forensic Psychology Dissertation Grant in Applied Law/Psychology. Thank you to these organizations for supplying me with the financial means to complete this study in the manner proposed and recognizing my attempts to provide a meaningful contribution to this research arena.

Last, but far from least, I want to extend gratitude to my phenomenal friends. Laura Young, I feel blessed to have met you and developed a bond over hallway dancing. Regardless of where we end up, I know you are going to continue to play a significant role in my life and I hope to provide you with the same support and joy you have given to me. Rob Cramer, thank you for all your consultation, random thoughts, and craziness...Tuscaloosa never would have been the same without you. Desiree Griffin, your smiles, hugs, and ability to quell my anxiety have meant the world to me. Thank you for helping me to survive this rollercoaster! Finally, to 
my best friends in Phoenix, Marisa Munoz and Kavita Sequeira, you have stuck by me through the past five years of being far away. You may never know what your continued presence in my life means to me. Now that this part of the path is almost over, I look forward to spending more quality time with each of you! 


\section{CONTENTS}

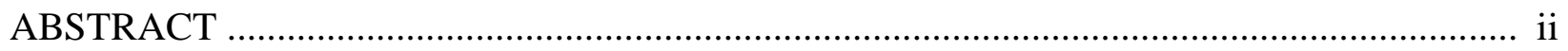

LIST OF ABBREVIATIONS AND SYMBOLS .............................................................. iv

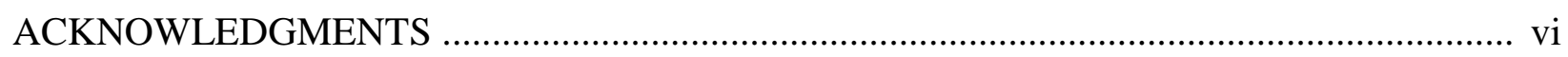

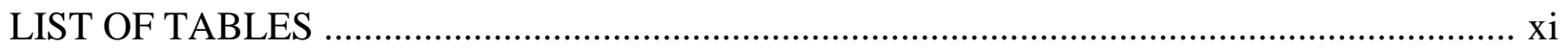

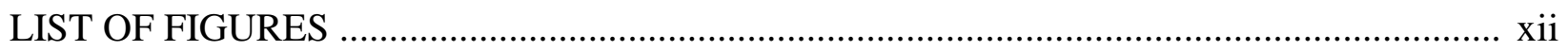

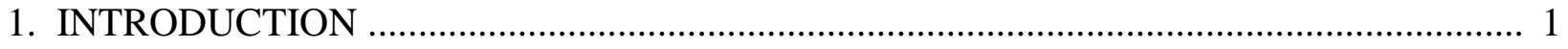

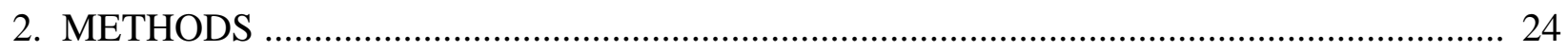

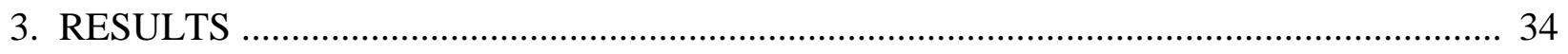

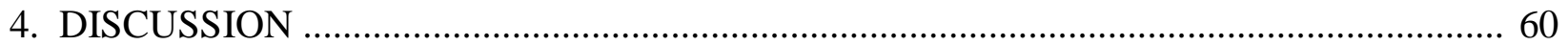

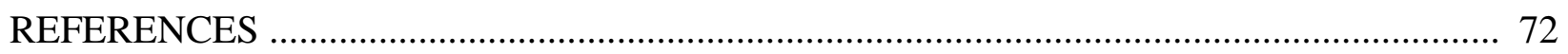

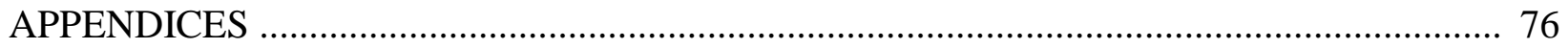




\section{LIST OF TABLES}

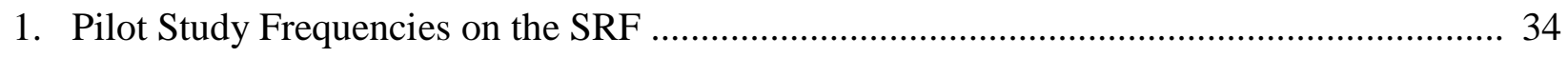

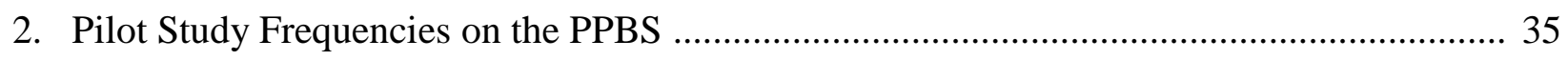

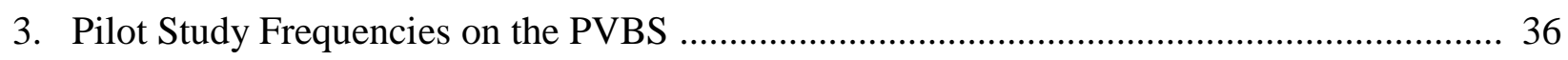

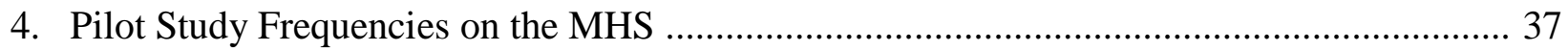

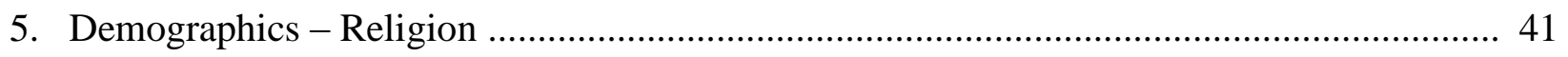

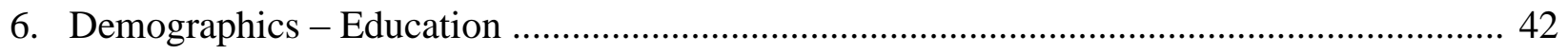

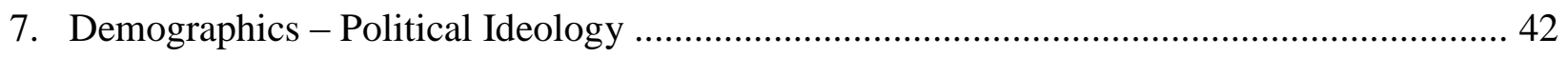

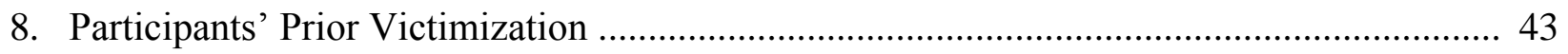

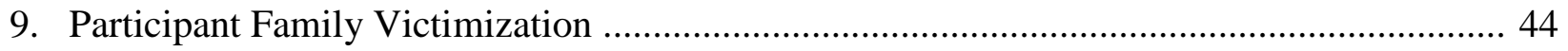

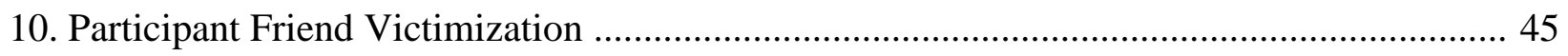

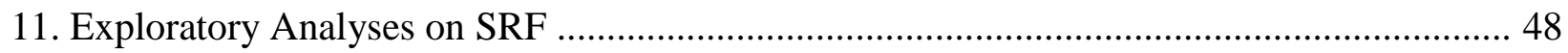

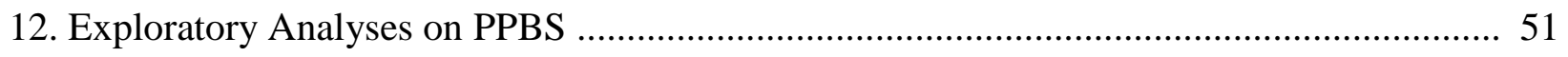

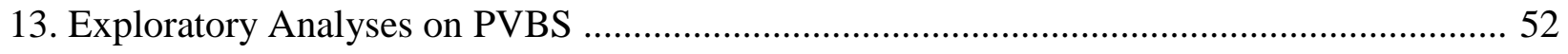

14. Exploratory Analyses on MHS …………………......................................................... 53

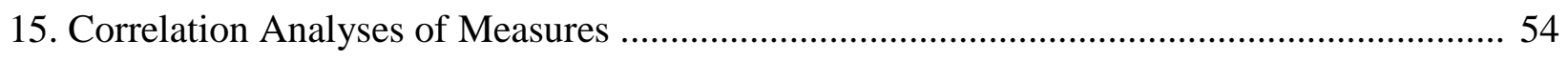

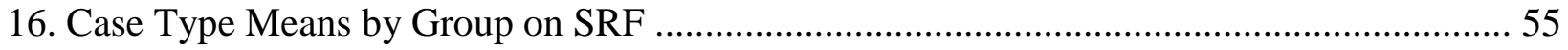

17. Victim Sexual Orientation Means by Group on the PPBS …………………………........... 57

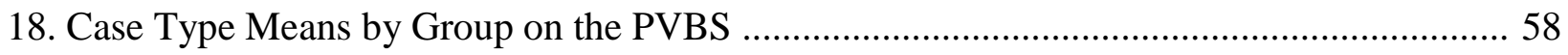




\section{LIST OF FIGURES}

1. Distribution of scores on the MHS...........................................69 


\section{INTRODUCTION}

The United States Congress (1994) has defined a hate crime as a "crime in which the defendant intentionally selects a victim... because of the actual or perceived race, color, religion, national origin, ethnicity, gender, disability, or sexual orientation of any person." Hate crimes vary in severity and can include threatening phone calls, destruction of property, harassment, physical or sexual assaults, and murder (Cowan, Heiple, Marquez, Khatchadourian, \& McNevin, 2005; Rayburn, Mendoza, \& Davison, 2003). Herek (2000) reported that in 1997 alone, lawenforcement agencies throughout the country recognized 1,102 hate crimes based on sexual orientation. Despite the federal government recognizing crimes against individuals who identify as lesbian, gay, bisexual, or transgender (LGBT) as hate crimes, there continue to be several state legislatures that do not (Anti-Defamation League, 2008).

The literature on hate crimes has focused primarily on the psychological effects these crimes have on the victims, as well as the underreporting of crimes to law enforcement agencies (Herek, Gillis, Cogan, \& Glunt, 1997; Herek, Gillis, \& Cogan, 1999; Lyons, 2006; McDevitt, Levin, \& Bennett, 2002). Studies that have looked at the prevalence of hate crimes based on sexual orientation show a large discrepancy between the number of crimes reported to law enforcement agencies and those reported in a research setting (Dunbar, 2006; Herek, Gillis, \& Cogan, 2002). These studies indicate there are significantly more hate crimes reported in a research setting than are reported to law enforcement agencies. Understanding such a 
discrepancy may play a role in helping to decrease hate crimes and the psychological distress associated with them.

Garnets, Herek, and Levy (1990) examined the psychological distress that can be produced by sexual orientation-based (SO) hate crimes. The authors found that SO hate crime experiences led victims to challenge their beliefs about their personal safety, invulnerability, and self-worth. The experience appears to have an impact on victims' core identity, which then leads them to view their sexuality as a source of danger, pain, and punishment, rather than intimacy and love. A later study by Herek, Gillis, and Cogan (1999) explored levels of psychological distress among lesbian, gay, and bisexual (LGB) victims of hate crimes and compared their levels of distress with those seen in non-victims and victims of non-bias crimes. With regard to psychological distress, Herek and colleagues found that victims of LGB hate crimes experienced significantly greater levels of depressive symptoms, traumatic stress symptoms, anxiety, and anger than victims of non-bias crime or non-victims. In addition, they found that victims of LGB hate crimes displayed "significantly less belief in the benevolence of people, more fear of crime, greater perceived vulnerability, and lower self-mastery" (p. 949) than did victims of non-bias crime and non-victims.

In a follow-up study, Herek, Gillis, and Cogan (2002) conducted interviews with 224 men and 226 women from the original study. They interviewed the victims with regard to the varieties of hate crimes experienced, how they determined that the crime was linked to their sexual orientation, and the reasons some of the victims chose not to report incidents to authorities. Herek and colleagues determined that the majority of SO hate crimes (i.e., physical 
assault, sexual assault, or murder) occurred in public places, whereas the non-bias person crimes ${ }^{1}$ (same list of crimes; however, not based on the individual's sexual orientation) were more likely to occur in private settings. In addition, hate crimes were more likely than non-bias crimes to have multiple perpetrators, and perpetrators that were male and strangers to the victims. The two most common explanations for not reporting the hate crime were (1) fear of discrimination and mistreatment by authorities, and (2) fear of potential negative consequences (e.g., harassment) resulting from having their sexual orientation publicly revealed.

Expanding on this research, Dunbar (2006) compared SO hate crimes with hate crimes based on racial/ethnic and religious bias, including the differences in the frequency of reporting for these crimes. The results of this study showed that lesbians of color were more often victims of violent crimes against their person than were any of the other victim groups. In addition, hate crimes associated with racial/ethnic and religious bias were more frequently reported to law enforcement than were SO hate crimes. The results also showed that there was a significant difference between the percentage of reported offenses based on the gender of the victim in SO hate crimes. Specifically, they found that $74 \%$ of gay men reported the offense, whereas only $66 \%$ of lesbian victims reported these offenses. Finally, Dunbar found that victims were less likely to report violent forms of aggression (e.g., physical assault, sexual assault, assault with a deadly weapon, and verbal threat of harm) than more minor offenses such as destruction of property, robbery, and hate graffiti.

\footnotetext{
${ }^{1}$ Same list of crimes (i.e., physical assault, sexual assault, or murder); however, not based on the individual's sexual orientation
} 


\section{Sexual Orientation and Sexual Prejudice in the Courtroom}

A slowly developing body of research has focused on the role sexual orientation plays within the courtroom. Prior to discussing this research, it is important to define the two terms most commonly used to describe sexual prejudice, homophobia and homonegativity. Homophobia is most often defined as the irrational fear, anxiety, hatred, and intolerance of homosexual individuals (Hill, 2000). In contrast, homonegativity, a term that was coined by Hudson and Ricketts (1980), is purported to be a politically neutral term that is used to describe any negative attitude (i.e., moral or intellectual disapproval) toward a homosexual individual regardless of the source of these attitudes.

Two studies have focused on the general effects of homophobia/homonegativity in the courtroom. In the first of these two studies, Sherrod and Nardi (1998) sought to identify potentially homophobic jurors during jury selection and developed profiles of the most homophobic mock jurors. They developed a 9-item Homophobia Scale and analyzed jurors' scores in relation to their demographics, lifestyle, and attitudes. Results showed that White and Latino males scored higher on the Homophobia Scale than all other comparison groups (i.e., African-American males and African-American, Latino, and White females). Among Whites, more homophobic respondents lived in the southern or central United States. In addition, the most significant correlate of homophobia was political conservatism. They also found the importance of religious beliefs to be positively correlated to higher scores on the Homophobia Scale for White and Latino males and females.

Hill (2000) conducted a subsequent study that looked at the influence of homonegativity on the verdict in sexual assault trial vignettes that involved either homosexual defendants or 
homosexual victims. In this study, Hill looked at the role sexual orientation of the defendant (always male) and alleged victim (both male and female) played in verdicts. Results indicated that homonegativity affected the guilt rating in the sexual assault trial that involved homosexuals; specifically, a homosexual male accused of sexually assaulting a heterosexual male was found guilty more often than was a heterosexual male who was accused of sexually assaulting either a heterosexual female or a homosexual male.

\section{Homosexuality and Stigma by Association}

As previously stated, the federal definition of a hate crime involves crimes committed against an actual or perceived member of a stigmatized group. Research has not yet been published that has examined differences in perceptions of hates crimes which involved an actual member of a group versus a perceived member. However, the limited literature that has examined courtesy stigma can provide a basis for the current study's hypotheses (Goffman, 1963; Sigelman, Howell, Cornell, Cutright, \& Dewey, 1991; Neuberg, Smith, Hoffman, \& Russell, 1994). The term "courtesy stigma" was first used by Goffman (1963) to describe the tendency for individuals that associate with a stigmatized person to be stigmatized or devalued solely based on this association. He suggested the fear of courtesy stigma may be a plausible explanation for why many individuals avoid associating with stigmatized individuals.

Sigelman, Howell, Cornell, Cutright, and Dewey (1991) examined whether courtesy stigma is present in associations with gay men. They posited that courtesy stigma occurs when two conditions are met: (1) the perceiver holds negative attitudes toward the stigmatized individual and (2) there must be evidence the person has a positive bond with the stigmatized individual. The authors utilized an entirely white male undergraduate student population in their 
study. The results of this study supported the courtesy stigma hypothesis, but only under specific conditions. Stigma was attributed to the stimulus male, but only when he actively chose to room with a gay male. This stigmatization was only seen in the participants with the most intolerant attitudes toward homosexuals. However, they found these intolerant participants did not view the stimulus male as negatively as the gay male. Further analysis of the results showed the intolerant participants believed that the stimulus male also had homosexual tendencies. The findings did not provide any evidence of stigmatization of the stimulus male when he involuntarily associated with a gay male (i.e., was assigned to room with a gay male). The authors concluded that courtesy stigmatization can occur when individuals assume that the associates of a stigmatized person share some of the person's "devalued attributes."

Neuberg, Smith, Hoffman, and Russell (1994) conducted two studies to determine whether there was evidence to support either destigmization of individuals when they interacted with positively viewed unstigmatized individuals, or whether association processes led to a stigma-by-association phenomenon (i.e., courtesy stigmatization). The participants in both studies were undergraduate males ( $n=104$ and $n=72$, respectively), who were asked to view a "live" conversation between two males (although the conversations were actually videotaped), in which the sexuality of the second male in the conversation was manipulated (either heterosexual or homosexual). The results of Neuberg and colleagues' studies did not support destigmatization of the second male when he was homosexual, regardless of whether the heterosexual male in the conversation was similar to the participant or of a high social status. However, the results did show when the second male was homosexual, he was stigmatized more when he interacted with heterosexual males that were similar to the participants. In addition, the results provided support 
for the stigma-by-association effect such that, when the second male was homosexual, more stigma was associated with the heterosexual male regardless of whether he was similar to the participant or held a high social status. The authors also noted that the heterosexual males of high social status were stigmatized more by their association with a homosexual male than those with lower social status. In general, the authors concluded their studies indicated the stigma-byassociation phenomenon does exist and is not buffered by social status or similarity to the observer.

Ingroup/Outgroup Theory and Assignment of Punishment

The social psychology literature has closely examined perceptions of individuals based on their similarity to (“ingroup") or difference from ("outgroup") self. Ingroup/outgroup theories are based on social identity theory (SIT), which posits that individuals tend to behave favorably toward individuals they perceive to be part of their "ingroup," and behave negatively toward those individuals they perceive to be part of their "outgroup." Individuals use these mechanisms to maintain a positive self-image and these mechanisms are most often referred to as "ingroup bias." In the current context, it is important to examine ingroup/outgroup theories as they can play a critical role in jury decision-making, particularly when examining how jurors may categorize the defendants or victims involved in a trial (Taylor \& Hosch, 2004). Two predominant theories have emerged that attempt to explain how these ingroup/outgroup mechanisms apply in the context of jury decision-making: (1) similarity-leniency hypothesis and (2) the "Black Sheep Effect." 


\section{Similarity-leniency hypothesis.}

Many juror decision-making studies have looked at the first of these theories, similarityleniency hypothesis, which proposes that jurors are more lenient toward defendants who are similar to themselves, rather than dissimilar (Abwender \& Hough, 2001; Kerr, Hymes, Anderson, \& Weathers, 1995; Sommors \& Ellsworth, 2000; Van Proojien, 2006; Wuensch, Campbell, Kesler, \& Moore, 2002). Kerr and colleagues (1995) found that when there was not overwhelming evidence of a defendant's guilt, mock jurors were more lenient toward defendants who practiced the same religion, as compared to defendants who practiced another religion. Further research has seen similar support for the similarity-leniency hypothesis in race-salient and non-race-salient trials, such that Black jurors rated Black defendants as less aggressive and less likely to be guilty than did White jurors (Abwender \& Hough, 2001; Sommors \& Ellsworth, 2000; Wuensch, Campbell, Kesler, \& Moore, 2002). These findings suggest jurors in hate crime trials may also be more lenient toward defendants they consider to be similar to themselves.

Van Prooijen (2006) also conducted several studies to examine the similarity-leniency hypothesis in relation to retributive reactions. Specifically, the author wanted to determine whether retributive reactions (i.e., a lay person's perceptions of what constitutes fair punishment) to ingroup and outgroup offenders were influenced by the certainty of an offender's guilt. He conducted four experiments that varied the type of offenses and whether the suspected offender was an ingroup or an outgroup member. The participants were also provided with information on the probability of the offender's guilt. The dependent variable in experiments one and two was the participant's retributive emotions, while participants' intentions for punishment was the dependent variable in experiment four. Experiments one through three provided participants 
with a statement indicating whether pieces of evidence established the suspect's guilt with $100 \%$ certainty or if guilty certainty was only $50 \%$ due to mixed pieces of evidence. The author manipulated guilt probability in experiment four by providing evidence to the participants which either established the suspect's guilt or suggested uncertainty about the suspect's guilt. The ingroup/outgroups used in each experiment were different nationalities (experiment one), different departments within a store (experiment two), and different universities (experiments three and four).

The results of Van Prooijen's (2006) experiments indicated that a suspect's social categorization has an influence on their moral judgments. In addition, the author found that the likelihood that the suspect was guilty moderated the effects of social categorization. $\mathrm{He}$ explained that "if guilt was certain, participants displayed more severe retributive reactions to ingroup than outgroup offenders, but when guilt was uncertain, participants showed less severe retributive reactions to ingroup than outgroup suspects" (p. 724). This same pattern was replicated in each of the four experiments he conducted. Van Prooijen also posited that these findings supported other social justice research which has shown a relation between morality, social categorizations, and group memberships. The results of these studies also provided further support for the similarity-leniency hypothesis; however, they do not explain why participants had more severe reactions to ingroup members whose guilt was certain.

\section{Black sheep effect.}

An additional theory of social group comparisons that may explain this phenomenon is the "Black Sheep Effect" (Marques, Yzerbyt, \& Leyens, 1988; Marques \& Yzerbyt, 1988). The black sheep effect, theorized by Marques, Yzerbyt, \& Leyens (1988), posited that ingroup 
members would actually be viewed more severely than outgroup members. For example, likeable ingroup members are viewed more positively than similarly likeable outgroup members, while unlikeable ingroup members are viewed more negatively than similarly unlikable outgroup members. This proposed effect was supported by several experiments with Belgian university students, with the ingroup/outgroup variable of nationality (Marques, Yzerbyt, \& Leyens, 1988). The findings suggested the desire to present the overall group in a positive light may lead to harsher evaluations of an unlikable ingroup member. An additional study by Marques and Yzerbyt (1988) included the ingroup/outgroup variable of academic focus (i.e., law versus philosophy students), and the results provided further evidence for the black sheep effect, in that ingroup members were evaluated to greater extremes than were outgroup members. In a hate crime trial, this may indicate that jurors would view defendants more harshly if they consider them as a member of their ingroup and therefore increase the likelihood of assigning a harsher sentence.

Taylor and Hosch (2004) also conducted a study that examined archival data from 418 felony cases whose outcomes were obtained through a trial by jury. The study included cases that involved defendants who were identified as either Hispanic or Caucasian and examined whether jury verdicts showed evidence of a similarity-leniency effect, an out-group punitiveness effect, or a black sheep effect. The authors did not find evidence for any of these effects when examining conviction rates or sentence lengths, regardless of the defendant's ethnicity or the jury composition. Examination of the archival data only indicated that verdict and sentence lengths were related to the strength of the prosecutorial evidence. The authors suggested that although previous studies showed similarity-leniency, out-group punitiveness, and black sheep effects 
may influence how individual's perceive defendants in criminal cases, these results may indicate that these effects do not predict collective decisions made by juries. However, the authors did note the results were correlational in nature and were not subjected to any deliberate experimental manipulation, which may have provided additional control for measuring these influences.

Finally, Van Prooijen and Lam (2007) examined whether individuals' perceptions of punishment were influenced by intergroup status and social categorizations. The authors used social identity theory as a basis for their predicted outcomes. The study looked specifically at retributive justice judgments for two different offenses: a wallet theft and a physical assault. The results of the study showed that when the ingroup has a higher status than the outgroup, respondents provided more punitive reactions to ingroup offenders than to outgroup offenders. However, when the status of the ingroup was low, equal levels of punitiveness were assigned to ingroup and outgroup offenders. Van Prooijen and Lam suggested it appears people are less concerned with rejecting an outgroup offender when the ingroup status is high as opposed to low, which is consistent with social identity theory. The authors further concluded that the psychological processes that influence peoples' punitive responses to outgroup offenders are triggered by the status level held by each group.

\section{Attribution Theories of Responsibility}

Attribution theories of responsibility assume that "an individual's perception of the causal relations in the environment is an important determinant of that person's reaction to environmental events" (Burger, 1981, p. 496). Since the mid-1950s, several theories have evolved that focus on how individuals assign responsibility of actions to other people. The first 
of these theories was developed by Heider in 1958. He posited that there are five different levels of responsibility attribution, and these levels of attribution depend upon the balance of internal and external attributions present in the situation. Several prominent theories expanded upon this theoretical framework of attributional processes.

One of the more empirically researched of these theories is that of defensive attribution. Defensive attribution theory (DAT) posits that the more serious the consequences of an accident or crime, the more responsibility will be assigned to individuals that are potentially at fault (Walster, 1966; Shaver, 1970). Fiske and Taylor (1991) provided an explanation of how defensive attribution occurs:

"As the consequences of an action become more severe, they become more unpleasant, and the notion that they might be accidental becomes less tolerable: The fear that the same thing might involve the self becomes a realistic possibility. Seeing the actions as avoidable and blaming a person for their occurrence makes the actions more predictable and hence avoidable by the self' (p. 85).

Support for DAT has been mixed (Burger, 1981; Chaikin \& Darley, 1973; Herzog, 2008;

Robbennolt, 2000; Shaver, 1970; Shaw \& McMartin, 1977). The first mixed findings were seen in the results of Shaver's (1970) study, which found that increases in attributed responsibility did not always correspond with increases in the severity of outcomes.

A body of research has since developed that focuses on defining the circumstances under which the predicted relationships of defensive attribution would hold. This literature suggests defensive attributions are not triggered unless the situation is highly relevant (i.e., situationally or personally) to the participants (Burger, 1981; Chaikin \& Darley, 1973; Herzog, 2008;

Robbennolt, 2000; Shaver, 1970; Shaw \& McMartin, 1977). Specifically, if an individual can relate to the situation, or if they feel highly similar to any of the individuals involved in the 
situation, then they will be less likely to assign responsibility. This proposed theory was best described by Vidmar and Crinklaw (1974, p. 114), who stated, "people need to believe that serious accidents could never happen to them, or if they could, that no one would ever blame them for the consequences."

Herzog (2008) expanded upon the two attributional possibilities DAT allows. The author stated perceived similarity can be either situational (i.e., the potential for the observer to be placed in a comparable situation to the victim) or personal (i.e., demographically shared characteristics); however, the degree of perceived personal similarity to the victim determines the direction of the blame attribution. Specifically, if an observer perceives a high amount of similarity to the victim, they are less likely to blame the victim, since they would not want to be blamed themselves if placed in the same situation (i.e., in-group favoritism). However, if the observer recognizes little or no similarity to the victim, they will attribute more blame to the victim (i.e., out-group prejudice).

Two meta-analyses reviewed the literature associated with DAT (Burger, 1981; Robbennolt, 2000). Burger (1981) reviewed 22 studies from 21 articles that examined the effect of outcome severity on measures of responsibility and blame. The results of this meta-analysis found a significant positive relationship between outcome severity and assignment of responsibility to the perceived perpetrator of an accident (e.g., the driver of a car who skidded on black ice and hit another car). In addition, when Burger examined the variables further, he found that less responsibility was attributed to the perpetrator as the severity of the accident increased when the participants in the study were personally and situationally similar to the perpetrator. 
Robbennolt (2000) attempted to build upon Burger's meta-analysis by including a wider range of responsibility-related measures (i.e., responsibility, blame, fault, liability, guilt, damages, and punishment). Robbennolt's final analysis included 67 articles published between 1966 and 1997. The results were separated by grouping studies based on their measure of responsibility. The author found a significant positive relationship between outcome severity and responsibility-related judgments for every type of responsibility measure used. However, Robbennolt noted the size of these relationships varied depending on judgment types (i.e., responsibility, blame, fault, liability, guilt, damages, and punishment), suggesting that the different judgments may be measuring different underlying concepts.

Robbennolt (2000) also looked at three potential moderating variables to these relationships: (1) outcome valence (i.e., positive or negative), (2) presentation medium (i.e., written vignette versus audio- or videotaped materials), and (3) participant type (i.e., juror or other adult participants versus student participants). The author found that the outcome valence acted as a moderating variable, such that when the outcome of a situation was positive (e.g., unexpected receipt of money for volunteer work, unexpected receipt of extra credit in a class for doing more hours involved in a research project), less responsibility was assigned for more severely positive outcomes. On the other hand, when the outcome of a situation was negative, more responsibility was assigned for more severe outcomes. Robbennolt also found that the relations discussed thus far were consistent across trial presentation mediums and participant type. However, the author noted that the magnitude of these effects varied across these variables. Specifically, outcome severity correlated more strongly with responsibility attributions in two situations: (1) when more realistic simulations (i.e., audiotape or videotape) 
were used and (2) when jurors or adult participants were used; these results were in comparison to studies that utilized written vignettes and/or student participants. However, the author noted the difference between presentation mediums was only "marginally significant" $(p=.066)$ and both types of presentation mediums produced a positive relationship between outcome severity and responsibility.

Only a few studies have examined attributions of responsibility in criminal cases.

Debotys and Dasgupta (1987) looked at attribution of responsibility and its relation to offenders and crime severity. They looked specifically at how the type of damage (either personal or property) and the extent of damage influenced perceived seriousness of a crime. They found that personal crimes (i.e., assault to the victim's head and neck) were considered to be more serious than property crimes, but only when the offender was not caught. They also found that higher ratings of seriousness were found as the negative consequences of a crime increased. They identified a strong relationship between responsibility and perceived seriousness of an offense. This relationship indicated participants attributed more responsibility to the offender as the severity of the crime increased. Thus, it is likely similar attributions of responsibility would be observed in trials of hate crimes.

Herzog (2008) examined whether or not DAT would provide an explanation for bias in the criminal justice system. Herzog described the main criticism of DAT as being the "limited and oversimplified" measurement of personal similarity and stated that multiple social identities need to be considered when measuring personal similarity, rather than just one specific identity dimension (e.g., gender, race, age). In addition, Herzog stressed most DAT research generally focused on either personal similarity or dissimilarity and also only examined either 
similarity/dissimilarity between the observer and either the offender or the victim. The purpose of Herzog's study was to examine how these multiple factors trigger defensive attributions in individuals examining various criminal acts. The author's goal was to empirically assess whether significant differences would be found in seriousness scores and punishment options (across various crime scenarios) based on the offenders and victims personal (dis)similarity to the respondents. Herzog's assumption was that these evaluations would vary based on the respondents', the offenders', and the victims' personal characteristics.

Herzog's (2008) study included a large sample $(n=1,650)$ of Israeli adults (aged 25 or 50 years). The results of the study indicated observers assigned higher scores to severity to crime scenarios in which the offender was personally dissimilar or a victim was personally similar to themselves than those crime scenarios with a similar offender or dissimilar victim. Herzog noted these results were only significant for those individuals aged 50 years, but were not significant among the younger respondents (25-years-old). When comparisons between gender and these results were examined, the author found these differences were reversed when the respondents were male, such that males assigned higher scores to scenarios in which there was a similar offender or dissimilar victim. Herzog emphasized that a high number of significance tests were conducted in the study, which may have increased the likelihood that some of the effects occurred by chance. However, despite this potential limitation, the author suggested this study provided further support for the idea that motivational processes, such as perceived personal similarity, impact how individuals perceive the seriousness of criminal acts and how they assign punishment to the offenders involved in those criminal acts. 


\section{Attribution Theory and Hate Crimes}

A recent article by Lyons (2006) examined the influence of social status on attributions of blame in two specific types of hate crime vignettes; those involving harassment (e.g., threaten to assault and/or threaten to kill) and those involving some level of violence (e.g., assault with moderate injury, and/or assault with severe injury). The researcher focused his study on how attribution of blame changed depending on the victim's status (e.g., race, gender, or sexual orientation). The results indicated that respondents (i.e., undergraduate students) attributed equal amounts of blame to male and female victims, but were influenced by the victim's and the perpetrator's race, as well as the victim's sexuality. He found that respondents assigned more blame to white offenders than to black offenders, and they attributed less blame to black victims than white victims. Although this may appear to be in direct contradiction to other studies, the author attributed these differences to the college student sample used for the study. He believed college students were particularly sensitive to the imbalance of power between black and white victims, as well as offenders. The author also noted that college students generally agree that racially motivated crimes are distinct from other incidents.

Unlike the sympathy shown for victims of racially motivated hate crimes, sympathy was not evident toward lesbian and gay victims. Lyons's results suggested homosexual victims were blamed more often than were heterosexual victims. When looking at respondents' attitudes toward homosexuality, Lyons found that more negative attitudinal scores were associated with increased blame for both homosexual and heterosexual victims; however, significantly more blame was still assigned to homosexual victims. On the other hand, only respondents with 
relatively pro-gay/lesbian attitudes attributed less blame to homosexual than to heterosexual victims.

Lyons explained the findings regarding the impact of victim sexuality on attributions of blame with the use of a stigma perspective model. He posited that increased attributions of blame are often associated with stereotypical beliefs about victims, particularly in relation to their social status. Application of this model to hate crimes would support the notion that victims with minority status (e.g., black, female, homosexual) would be found to be more at fault than victims of majority status. Lyons speculated that, in relation to attribution of blame, the stigma perspective model would be most evident when the evaluators look at the individual's status (either victim or offender) in relation to ingroup/outgroup characteristics. If this assumption was applied to a SO hate crime trial, it may suggest that jurors who are heterosexual assign more blame to a homosexual victim and less blame to a heterosexual perpetrator.

\section{Juror Perceptions and Attitudes in Hate Crime Trials}

Little research has been conducted on juror perceptions and attitudes that are specifically tied to trials that involve hate crimes; however, it is important to examine the literature that does exist. Of the limited number of articles that have explored these factors (Lyons, 2006; Cramer et al., 2008; Rayburn \& Davison, 2002; Rayburn, Mendoza, \& Davison, 2003; Saucier et al., 2006), only two have examined the applicability of a jury decision-making model (Cramer et al., 2008; Saucier et al., 2006). The following paragraphs will review this research and will address the findings most pertinent to the current study.

The first study that examined these perceptions was conducted by Rayburn and Davison (2002). These researchers looked at the thoughts and feelings of individuals who were exposed 
to a scenario about a conspiracy to commit an antigay hate crime. They found that compared to a non-hate crime scenario ${ }^{2}$, the hate crime scenario resulted in participants having a greater desire to physically aggress against the perpetrator and to be more protective of the victim. The authors concluded that when witnessing hate crimes, bystanders have more favorable behavioral intentions toward victims than perpetrators, even for those participants who expressed antigay attitudes.

Rayburn and Davison (2002) also found that those participants who expressed antigay attitudes expressed significantly more anger toward the hate crime victim, were more disapproving of the hate crime victim, and were more supportive of the hate crime perpetrators. However, these patterns associated with antigay attitudes were not found in the non-hate crime scenario. The authors concluded that although the participants with antigay attitudes condemned the hate crime victim's lifestyle and were supportive of their punishment, they were still no less likely to protect the hate crime victim. The authors noted that one weakness of their study was they did not address the question of the participants' impression of the victim's culpability; therefore, they conducted a follow-up study that addressed this limitation.

In their follow-up study, Rayburn, Mendoza, and Davison (2003) investigated bystanders' immediate impressions of blame, both for the victim and the perpetrator, using a person perception method. To do this they utilized four vignettes that differed only on the basis of the bias associated with the hate crime: (1) race-based, (2) religion-based, (3) sexual orientation-based, and (4) a crime of unknown motivation. Immediately after reading one of the

2 The authors did not provide a specific description of either the non-hate crime or hate crime scenarios in their article. 
assigned vignettes, participants rated both the victim and perpetrator on their perceived degree of culpability.

Rayburn, Mendoza, and Davison (2003) found participants attributed less blame to hate crime victims than non-hate crime victims and attributed more blame to hate crime perpetrators. In addition, female participants were more likely than male participants to view all crime victims (regardless of motivation for the crime) as less culpable and all perpetrators to be more responsible for their behavior. To examine differences between prejudiced and non-prejudiced participants, the authors collapsed their three prejudice measures (i.e., Anti-Semitism Scale, Modern Racism Scale, and Attitudes Toward Lesbians and Gays Scale) to produce an overall Prejudice Index. They noted these three prejudice scales were moderately related (significant correlations from .318 to .398 ). When they examined differences between prejudiced and nonprejudiced participants (dichotomized through a median split), they found the presence of prejudice was associated with more blame for all crime victims and less blame for all perpetrators across all types of hate crimes. In addition, prejudiced minority participants assigned less blame to hate crime victims and more blame to non-hate crime victims, whereas prejudiced non-minority participants assigned more blame to hate crime victims and less blame to non-hate crime victims. Rayburn, Mendoza, and Davison (2003) suggested these results may indicate "that people who can identify with the victim... react to hate crime victims in a less punishing way" (p. 1070).

Saucier, Brown, Mitchell, and Cawman (2006) also examined beliefs related to how hate crimes (based on race, gender, or sexual orientation) should be punished in comparison to similar offenses that were not believed to be motivated by bias. The results suggested the presence of 
bias on the basis of race and gender. Specifically, respondents gave more severe sentences to perpetrators whose victim was an African American male, a Jewish male, a Latino male, an Asian male, or a gay male. More severe sentences were also recommended for crimes that more closely fit the definition of a hate crime. These differences were significant only when the crime was simple assault; differences were not evident when the crime was aggravated assault. In general, these results showed that mock jurors render harsher sentences for hate crimes only up to a certain point.

Finally, Cramer and colleagues (2008) conducted a study that examined victim blame and sentencing outcome with regard to a fictitious hate-based murder. Using an undergraduate sample, the authors conducted a vignette-based study in which they manipulated victim sexual orientation and the presence of evidence that the murder was a hate crime. The results of the study indicated that victim blame was lower when the victim was gay (across all conditions) and a more severe sentence was assigned when evidence of a hate crime was present. Cramer and colleagues also identified several moderators for these effects; included among them were authoritarianism and sexual prejudice (i.e., homonegativity). Mock jurors low in authoritarianism and high in homonegative views were more likely to assign severe punishments (i.e., the death penalty). In addition, mock jurors that were high in homonegative views attributed more blame to victims.

\section{The Current Study}

Previous research has examined the influence of juror sexual orientation in criminal cases and jury decision-making processes in hate crimes. To date, there has been no published research identified which has looked at juror perceptions of sexual orientation-based (SO) hate 
crimes on the basis of severity of the crime or the effect of victim sexual orientation on sentencing decisions. The primary focus of this study was to identify factors that influence jury decision-making when faced with a SO hate crime. More specifically, the goal was to identify the factors that influence the relationship between severity of crime and assignment of punishment to the perpetrator. The differences in assignment of punishment were examined across three different levels of hate crime: misdemeanor assault, felony assault, and attempted murder. Since a hate crime is defined as having been committed against a member of a specific group, or a perceived member of that group, the present study explored whether the victim's sexual orientation (i.e., homosexual vs. heterosexual perceived as homosexual) moderates the relation between severity of crime and assignment of punishment. Juror sexual prejudice (i.e., homonegativity) was also examined as a potential moderator of this relation.

A secondary focus of this study was to examine whether jurors' perceptions of perpetrator and victim blame vary based on the severity of the crime and the victim's sexual orientation. Previous literature has shown juror sexual prejudice influences jurors' perceptions and decision-making processes in SO hate crimes (e.g., Cramer et al., 2008, etc.); therefore, this study explored whether juror sexual prejudice (i.e., homonegativity) moderates each of the described relations. The proposed study is the first identified study to examine this factor using a representative jury pool.

\section{Hypotheses}

Question 1: How do victim sexual orientation and homonegativity influence the relationship between severity of crime and assignment of punishment? 
H1: Jurors will assign higher punishments to the perpetrator when the victim is heterosexual than when the victim is homosexual. However, these differences will only be significant for those individuals high in homonegativity. These differences will also be most pronounced in the least severe crime (i.e., misdemeanor assault) and will become non-significant in the most severe crime (i.e., attempted murder).

Question 2: Do jurors' perceptions of blame in sexual orientation-based hate crimes vary based on the severity of the crime and the victim's sexual orientation? Does homonegativity moderate these relations?

H2: There will be a positive relation between severity of the crime and jurors' perceptions of perpetrator blame.

H3: A negative relation will be found between severity of the crime and jurors' perceptions of victim blame.

H4: Higher levels of blame will be attributed to the perpetrator when the victim is heterosexual (perceived as homosexual) than when the victim is homosexual.

H5: Lower levels of blame will be attributed to the victim when the victim is heterosexual (perceived as homosexual) than when the victim is homosexual.

H6: Homonegativity will moderate the relations seen in Hypotheses two thru five. The effect sizes of the relations between severity of crime and perceptions of perpetrator and victim blame will decrease at higher levels of homonegativity. In addition, the effect sizes of the relations between victim sexual orientation and perceptions of perpetrator and victim blame will decrease at lower levels of homonegativity. 


\section{METHODS}

\section{Participants}

Participants were recruited from jury pools across several counties located in the state of Alabama (See Procedures section). Participants included individuals who presented to the courthouse for jury duty. A medium effect size was chosen to be used in determining the sample size of this study due to the lack of any applied research pertaining to the majority of questions that were examined. The choosing of a medium effect size was based on Lipsey's (1990) metaanalyses of mental health and educational interventions, which found that the average effect size of these studies fell in the medium range. According to Cohen (1992), the sample size needed to measure the severity of crime variable for the current study with an alpha level of .05 , statistical power of .80 , and a medium effect size $(r=.25)$ was a minimum of 25 participants per group. This indicated a total of 150 participants needed, as there were six groups in this study (See Materials section). The sample size needed to measure victim sexual orientation as an independent variable with the same parameters would be 64 participants or a total of 128 participants. Therefore, the current study required a total of 150 participants to ensure adequate strength for measurement of each of the independent variables included. The final sample obtained for this study consisted of 238 participants. 


\section{Materials}

Demographics Form. (See APPENDIX A; Flesch-Kincaid grade level 3.0). A brief demographics form was used to collect data regarding participants' age, sex, race, religion, education, political ideology, jury service experience, prior involvement in the criminal justice system, and crime victimization history. This information was used to examine whether observed differences (if any) were related to these factors.

Trial Vignettes. A series of trial vignettes were used in the present study (See APPENDICES B, C, and D; Flesch-Kincaid grade levels 5.5, 5.3, and 5.5). The trial vignettes were developed by searching a case law database for a crime which met the requirements for one of the levels of crime included in the present study. Identifying information was changed and then alterations were made to the information needed for manipulation in the study. Each vignette contained summary information of a sentencing phase scenario in which a heterosexual male perpetrator was convicted of a crime against a male victim. With the exception of the experimental manipulations (i.e., severity of crime and victim sexual orientation), each vignette contains the same information. The demographics that remain constant in the vignettes are based on Herek, Gillis, and Cogan's (2002) research which identified these demographics as characteristic of the majority of perpetrators against gay males and lesbians. The six conditions were as follows: (1) misdemeanor assault - homosexual victim; (2) misdemeanor assault heterosexual victim; (3) felony assault - homosexual victim; (4) felony assault - heterosexual victim; (5) attempted murder - homosexual victim; (6) attempted murder - heterosexual victim.

Sentencing Recommendation. (See APPENDIX E; Flesch-Kincaid reading level 6.7). The Sentencing Recommendation Form (SRF) is a scale developed for use in the current study. 
The SRF is a rating scale on which participants provided a sentencing recommendation for the perpetrator described in the trial vignette. This scale was not empirically validated; however, it was rooted in psychological theory. Although the points on the scale are not equidistant, they were chosen to be reflective of psychologically meaningful differences based on the escalation of sentences for crimes. For example, an increase in months for minor crimes is thought to be viewed as a meaningful increase in required sentence, whereas an increase of one or more years is likely to be viewed as a meaningful increase for more severe crimes.

Perpetrator Blame. (See APPENDIX F; Flesch-Kincaid reading level 7.8). Perpetrator blame was measured using the Perception of Perpetrator Blame Scale (PPBS), which was developed by Rayburn and colleagues (2003). The scale measures the degree of culpability or blame participants assign to a perpetrator, and consists of 14 bipolar adjective pairs that are rated on a seven-point scale. These scores are then summed to obtain a composite perpetrator blame score; higher scores reflect a higher level of perpetrator blame. Rayburn and colleagues (2003) reported an internal consistency of .85 for the PPBS. The current study yielded an internal consistency (Cronbach's Alpha) of .77 on the PPBS.

Victim Blame. (See APPENDIX G; Flesch-Kincaid reading level 6.9). Victim blame was measured using the Perception of Victim Blame Scale (PVBS), which was developed by Rayburn and colleagues (2003). The scale measures the degree of culpability or blame participants assign to a victim, and consists of 14 bipolar adjective pairs rated on a seven-point scale. These scores are then summed to obtain a composite victim blame score; higher scores reflect a higher level of victim blame. Rayburn and colleagues (2003) reported an internal consistency of .90 for the PVBS. In addition, Cramer and colleagues (2008) reported a 
Cronbach's Alpha of .94 in their investigation. The current study obtained an internal consistency (Cronbach's Alpha) of .89.

Homonegativity. (See APPENDIX H; Flesch-Kincaid reading level 4.7). The Modern Homonegativity Scale (MHS) was developed by Morrison and Morrison (2002) to assess participants' attitudes toward homosexuals (i.e., homonegativity). The authors created two parallel forms of the MHS, one that assesses homonegativity toward gay men (MHS-G) and one that assesses homonegativity toward lesbians (MHS-L). The MHS-G version was utilized in the present study. The MHS-G is a twelve-item measure that evaluates homonegativity on a fivepoint Likert scale that ranges from 1 (strongly disagree) to 5 (strongly agree); higher total scores reflect a higher level of homonegativity. Examination of internal consistency for MHS in the current study yielded a Cronbach's Alpha of .83.

Morrison and Morrison (2002) examined the psychometric properties of the MHS-G through four separate studies. A total of 943 heterosexual university students (385 males; 558 females) who ranged in age from 17 to 51 years were used in these studies. The results of study 1 showed positive correlations between the MHS and political conservatism, religious behavior, and religious self-schema ( $r=.20$ to .53 ), which provided some preliminary evidence for the construct validity of the MHS. Study 2 further examined the construct validity of the scale and showed the MHS was positively correlated with neosexism $(r=.57$ to .59$)$. In addition, the authors found scores on the MHS were not significantly correlated with scores on a measure of social desirability bias $(r=-.03)$, and as such, they opined these measures may provide more accurate views of negative attitudes toward gay men. The results of study 3 indicated the MHS possesses adequate reliability (alpha coefficient of .91 for both males and females). In Morrison 
and Morrison's (2002) final study, an experimental manipulation was conducted to examine whether behavioral expressions of modern homonegativity would be correlated with higher scores on the MHS. The results indicated that those individuals who received high scores on the MHS showed a greater tendency to avoid sitting with an individual who was presumed to be homosexual. This occurred within a condition that allowed their choices to be covert, as they could justify their seating choice on nonprejudicial grounds.

Feedback Questionnaire. (See APPENDIX I; Flesch-Kincaid reading level 6.6). A brief feedback questionnaire was created to obtain feedback from participants on the study. The questionnaire included two questions. The first asked about the clarity of the measures and the second asked about participants' comfort level during the study (i.e., did participating cause them any psychological discomfort). If the participant responded yes to either of these questions, they were requested to provide further information on the unclear portions or portions which made them feel uncomfortable.

\section{Procedures}

Pilot study.

A pilot study was conducted to explore the feasibility and efficacy (i.e., adequate variability in responses) of the measures and procedures which were to be utilized in the current study. Participants were recruited from the undergraduate psychology subject research pool at The University of Alabama. The sessions were conducted in assigned classrooms at the university. Once all participants arrived at each session, the researcher provided each participant with a hard copy of the participant information sheet (See APPENDIX J; Flesch-Kincaid grade level of 8.7), which outlined each participant's rights with regard to confidentiality and 
withdrawal from participation. The researcher read the participant information sheet aloud to the entire group of participants. The researcher then asked the group if there were any questions and informed participants they could ask questions at anytime during or after the study. Contact information for the researchers was included on the participant information sheet and participants were verbally directed to this information before proceeding with the study. Once all relevant information was addressed participants signed and dated the participant information sheet. The researchers then collected the participant information sheets and distributed the rest of the questionnaires separately to ensure confidentiality. Coded numbers were utilized on each packet to ensure participant anonymity.

Survey packets for the six experimental conditions were randomly distributed to participants within each of the pilot study data collection sessions. Materials were completed in the following order: (1) demographics form, (2) trial vignette, (3) SRF, (4) PPBS, (5) PVBS, (6) the MHS, and (7) the feedback questionnaire. Upon completion of the questionnaires, participants were individually debriefed on the full purpose of the study and the suspected relation of the variables being investigated. Each participant was given a debriefing form (See APPENDIX K), which contained the information provided verbally during the debriefing session. Participants were given the opportunity to ask questions before they left the session. To protect the study manipulation, the participants were asked not to discuss the nature of the study with anyone. The study took approximately 20 to 30 minutes to complete.

In addition to the measures included in the current study (see Materials section), a measure titled the Attribution of Fault Scale (AFS; See APPENDIX L) was developed for this study to measure the attribution of fault assigned to the perpetrator and the victim. Scores on the 
AFS ranged from 1 to $7 ; 1$ indicating they viewed the crime to be entirely the victim's fault, 4 indicating an equal distribution of fault between the victim and the perpetrator, and 7 indicating the perception that the crime was entirely the perpetrator's fault. This measure was administered after the SRF in the previously described ordering of materials. A total of 78 participants (18 males, 60 females) were included in this pilot study, with information from 13 participants included within each of the experimental conditions. Each participant completed all of the measures and items included within the study.

\section{Current study.}

Data was collected for the current study at courthouses across Alabama during jury selection days. Letters of support were obtained from presiding judges in Jefferson (Bessemer Division), Fayette, Lamar, and Pickens counties, which allowed the researchers access to the jury pools in these jurisdictions. On collection dates, the presiding judge informed members of the jury pool that a researcher from The University of Alabama was conducting a research study on juror perceptions. The presiding judge then informed the jury pool they were under no obligation to participate, but they would be compensated ten dollars for their time if they chose to participate. The attention of the jury pool was then directed to the researcher as the presiding judge left the courtroom. All interactions with the jury pool occurred following the general jury pool selection process, but prior to their separation into different courtrooms for selection in specific cases and completion of their jury duties for the day.

Consistent with the pilot study, each data collection session began by the researcher addressing the entire jury pool and verbally providing information about the study as outlined in the informed consent form (ICF; which replaced the participant information sheet from the pilot 
study). Individuals who wished to participate were then provided with two copies of the ICF (See APPENDIX M) which outlined participant rights with regard to confidentiality, withdrawal from participation, and compensation ( $\$ 10$ per participant for compensation for their time). On the ICF, it was stated that the study related to how different aspects of a trial impact a juror's perceptions of the case. Disclosure of the full purpose of the study occurred after completion of the study to prevent the study manipulation from being compromised. Similarly, to prevent social desirability bias that may occur from knowledge that the crime is considered to be a SO hate crime, the ICF did not mention the specific type of crime involved. After being provided with the informed consent form, the participants were notified they could ask questions at any time during or after the study.

Contact information for the researchers was included on the ICF and participants were verbally directed to this information before proceeding with the study. Once all relevant information had been addressed, interested participants signed and dated one of the ICFs and were instructed to keep the second copy for their own records. Individuals who did not wish to participate were asked to return their forms to the researcher. The researchers then collected the ICFs and distributed the questionnaires to the remaining participants. Coded numbers were utilized on each packet to ensure participant anonymity.

Matching the pilot study procedures, survey packets for the six experimental conditions were randomly distributed to participants within each of the data collection sessions. At all courthouses, the study was conducted in the jury pool room. One change made to the procedures following completion of the pilot study was a re-organization of the materials completed, such that the demographics form was administered following the MHS. This change was made to 
allow the inclusion of a question at the end of the demographics form which inquired about what the participants believed the study was trying to examine. This was done as a manipulation check to determine whether participants were able to determine the true nature of the study prior to completing the study, which could have impacted the participants' responses. As a result of this change, all participants completed the materials in the following order: (1) trial vignette, (2) SRF, (3) PPBS, (4) PVBS, (5) the MHS, (6) demographics form, and (7) feedback questionnaire. Upon completion of the questionnaires, and consistent with the pilot study, participants were individually debriefed on the full purpose of the study and the suspected relation of the variables being investigated. At this time, participants were given the opportunity to ask questions, all of which were answered during the debriefing process. Each participant was then given two copies of the debriefing/second consent forms (See APPENDIX N) that contained the information provided verbally during the debriefing sessions. The debriefing/second consent form in the current study differs from the debriefing form utilized in the pilot study. Additions were made to the end of the debriefing document, which provided each participant with the option to either allow their information to be utilized within the study or to have their information removed from the study following debriefing, as indicated by signing the appropriate space on the debriefing form. They were also provided with an additional copy of the debriefing form to maintain for their own records. Packets for those individuals who requested their information be removed were maintained separately and the data contained in their information packets was destroyed and not utilized in the current study $(n=4)$. Each session took approximately 30 to 40 minutes to complete. All participant informed consent and debriefing forms were maintained separately from the questionnaire packets. This was done to 
ensure that a connection could not be made between an individual and their answers to the questionnaires. 


\section{RESULTS}

\section{Pilot Study}

As noted in the Procedures section, a pilot study was conducted prior to the completion of the current study to assist in determining the feasibility and efficacy of the proposed procedures and measures. An examination of the descriptive statistics and frequencies (See Tables 1, 2, 3, and 4) for each experimental condition showed adequate variability in the range of scores for the SRF, PPBS, PVBS, and MHS.

Table 1

Pilot Study Frequencies on the SRF

\begin{tabular}{|c|c|c|c|c|c|c|}
\hline Score & M-Homo & M-Hetero & F-Homo & F-Hetero & AM-Homo & AM-Hetero \\
\hline 1 (No Punish) & 0 & 0 & 0 & 0 & 0 & 0 \\
\hline 2 (Probation) & 0 & 4 & 2 & 0 & 0 & 0 \\
\hline 3 (1 month) & 4 & 0 & 0 & 2 & 0 & 0 \\
\hline 4 (3 months) & 5 & 4 & 1 & 1 & 0 & 0 \\
\hline 5 (6 months) & 4 & 2 & 3 & 2 & 1 & 1 \\
\hline 6 (12 months) & 0 & 2 & 3 & 4 & 0 & 0 \\
\hline 7 (3 years) & 0 & 0 & 1 & 3 & 2 & 2 \\
\hline 8 (5 years) & 0 & 1 & 2 & 1 & 1 & 0 \\
\hline 9 (7 years) & 0 & 0 & 0 & 0 & 1 & 2 \\
\hline 10 (10 years) & 0 & 0 & 1 & 0 & 2 & 1 \\
\hline 11 (15 years) & 0 & 0 & 0 & 0 & 1 & 1 \\
\hline 12 (20 years) & 0 & 0 & 0 & 0 & 1 & 2 \\
\hline 13 (30 years) & 0 & 0 & 0 & 0 & 3 & 3 \\
\hline 14 (Life) & 0 & 0 & 0 & 0 & 1 & 1 \\
\hline
\end{tabular}


Table 2

Pilot Study Frequencies on the PPBS

\begin{tabular}{|c|c|c|c|c|c|c|}
\hline Score & M-Homo & M-Hetero & F-Homo & F-Hetero & AM-Homo & AM-Hetero \\
\hline 32 & 0 & 0 & 1 & 0 & 0 & 0 \\
\hline 58 & 0 & 0 & 1 & 0 & 0 & 0 \\
\hline 61 & 0 & 1 & 0 & 0 & 0 & 0 \\
\hline 62 & 0 & 0 & 0 & 0 & 0 & 1 \\
\hline 63 & 0 & 1 & 0 & 0 & 0 & 0 \\
\hline 64 & 1 & 0 & 0 & 0 & 0 & 0 \\
\hline 67 & 0 & 0 & 0 & 1 & 0 & 0 \\
\hline 69 & 0 & 2 & 0 & 1 & 0 & 0 \\
\hline 70 & 1 & 1 & 1 & 0 & 0 & 0 \\
\hline 71 & 0 & 0 & 0 & 0 & 0 & 1 \\
\hline 72 & 0 & 1 & 0 & 1 & 0 & 0 \\
\hline 73 & 2 & 1 & 1 & 0 & 0 & 0 \\
\hline 74 & 2 & 0 & 0 & 1 & 0 & 0 \\
\hline 75 & 0 & 1 & 0 & 1 & 1 & 0 \\
\hline 77 & 0 & 1 & 0 & 0 & 1 & 0 \\
\hline 78 & 0 & 0 & 2 & 0 & 1 & 1 \\
\hline 79 & 1 & 1 & 1 & 1 & 0 & 1 \\
\hline 80 & 0 & 1 & 1 & 0 & 1 & 1 \\
\hline 81 & 1 & 0 & 0 & 0 & 0 & 0 \\
\hline 82 & 0 & 1 & 0 & 0 & 1 & 0 \\
\hline 83 & 1 & 0 & 2 & 1 & 4 & 0 \\
\hline 84 & 2 & 0 & 1 & 0 & 0 & 1 \\
\hline 85 & 0 & 0 & 0 & 1 & 1 & 0 \\
\hline 86 & 0 & 0 & 1 & 0 & 1 & 0 \\
\hline 87 & 1 & 0 & 0 & 0 & 0 & 2 \\
\hline 89 & 0 & 0 & 0 & 0 & 1 & 0 \\
\hline 90 & 0 & 0 & 1 & 1 & 1 & 2 \\
\hline 91 & 1 & 1 & 0 & 2 & 0 & 0 \\
\hline 92 & 0 & 0 & 0 & 1 & 0 & 0 \\
\hline 95 & 0 & 0 & 0 & 0 & 0 & 2 \\
\hline 98 & 0 & 0 & 0 & 1 & 0 & 1 \\
\hline
\end{tabular}


Table 3

Pilot Study Frequencies on the PVBS

\begin{tabular}{|c|c|c|c|c|c|c|}
\hline Score & M-Homo & M-Hetero & F-Homo & F-Hetero & AM-Homo & AM-Hetero \\
\hline 14 & 2 & 1 & 0 & 2 & 0 & 1 \\
\hline 15 & 0 & 0 & 0 & 0 & 1 & 0 \\
\hline 17 & 1 & 0 & 0 & 0 & 0 & 1 \\
\hline 20 & 1 & 1 & 3 & 1 & 1 & 0 \\
\hline 21 & 0 & 1 & 0 & 0 & 1 & 0 \\
\hline 22 & 1 & 1 & 1 & 0 & 0 & 1 \\
\hline 23 & 0 & 1 & 0 & 0 & 2 & 1 \\
\hline 24 & 2 & 0 & 0 & 0 & 1 & 0 \\
\hline 25 & 0 & 0 & 0 & 0 & 0 & 1 \\
\hline 26 & 3 & 1 & 2 & 0 & 0 & 0 \\
\hline 27 & 0 & 0 & 0 & 0 & 1 & 0 \\
\hline 28 & 1 & 1 & 1 & 2 & 1 & 1 \\
\hline 29 & 0 & 0 & 1 & 0 & 1 & 0 \\
\hline 30 & 0 & 0 & 0 & 0 & 0 & 2 \\
\hline 31 & 0 & 0 & 0 & 0 & 2 & 1 \\
\hline 32 & 1 & 1 & 0 & 0 & 1 & 0 \\
\hline 33 & 1 & 0 & 0 & 0 & 0 & 1 \\
\hline 34 & 0 & 1 & 0 & 2 & 0 & 1 \\
\hline 35 & 0 & 1 & 0 & 0 & 0 & 0 \\
\hline 37 & 0 & 0 & 1 & 0 & 0 & 0 \\
\hline 38 & 0 & 2 & 0 & 0 & 0 & 0 \\
\hline 39 & 0 & 0 & 0 & 2 & 1 & 0 \\
\hline 40 & 0 & 0 & 0 & 0 & 0 & 1 \\
\hline 41 & 0 & 0 & 0 & 1 & 0 & 0 \\
\hline 42 & 0 & 0 & 0 & 1 & 0 & 1 \\
\hline 44 & 0 & 0 & 0 & 1 & 0 & 0 \\
\hline 47 & 0 & 1 & 0 & 0 & 0 & 0 \\
\hline 48 & 0 & 0 & 1 & 0 & 0 & 0 \\
\hline 52 & 0 & 0 & 1 & 0 & 0 & 0 \\
\hline 53 & 0 & 0 & 0 & 1 & 1 & 0 \\
\hline 57 & 0 & 0 & 1 & 0 & 0 & 0 \\
\hline 68 & 0 & 0 & 1 & 0 & 0 & 0 \\
\hline
\end{tabular}


Table 4

Pilot Study Frequencies on the MHS

\begin{tabular}{|c|c|c|c|c|c|c|}
\hline Score & M-Homo & M-Hetero & F-Homo & F-Hetero & AM-Homo & AM-Hetero \\
\hline 17 & 1 & 0 & 0 & 0 & 0 & 0 \\
\hline 18 & 1 & 1 & 0 & 0 & 0 & 1 \\
\hline 24 & 0 & 0 & 0 & 0 & 0 & 1 \\
\hline 25 & 0 & 0 & 0 & 0 & 0 & 1 \\
\hline 26 & 0 & 1 & 0 & 2 & 0 & 0 \\
\hline 27 & 0 & 0 & 0 & 2 & 0 & 0 \\
\hline 28 & 1 & 0 & 1 & 0 & 0 & 1 \\
\hline 29 & 0 & 1 & 1 & 1 & 1 & 1 \\
\hline 30 & 0 & 2 & 0 & 0 & 1 & 0 \\
\hline 31 & 1 & 2 & 0 & 0 & 1 & 1 \\
\hline 32 & 2 & 0 & 0 & 0 & 2 & 1 \\
\hline 34 & 1 & 0 & 1 & 2 & 1 & 0 \\
\hline 35 & 1 & 0 & 1 & 0 & 2 & 0 \\
\hline 36 & 0 & 0 & 4 & 0 & 0 & 0 \\
\hline 37 & 0 & 1 & 0 & 0 & 0 & 0 \\
\hline 38 & 0 & 1 & 0 & 0 & 0 & 1 \\
\hline 39 & 1 & 0 & 1 & 1 & 1 & 0 \\
\hline 40 & 1 & 0 & 0 & 0 & 0 & 1 \\
\hline 41 & 1 & 1 & 0 & 1 & 0 & 0 \\
\hline 42 & 0 & 1 & 1 & 1 & 0 & 0 \\
\hline 43 & 0 & 1 & 0 & 0 & 1 & 0 \\
\hline 44 & 1 & 0 & 0 & 0 & 0 & 0 \\
\hline 45 & 0 & 1 & 0 & 2 & 0 & 1 \\
\hline 46 & 1 & 0 & 1 & 0 & 0 & 1 \\
\hline 47 & 0 & 0 & 0 & 1 & 1 & 0 \\
\hline 50 & 0 & 0 & 1 & 0 & 0 & 0 \\
\hline 52 & 0 & 0 & 0 & 0 & 1 & 1 \\
\hline 54 & 0 & 0 & 1 & 0 & 0 & 0 \\
\hline 56 & 0 & 0 & 0 & 0 & 1 & 0 \\
\hline 57 & 0 & 0 & 0 & 0 & 0 & 1 \\
\hline
\end{tabular}

Obtained scores on the SRF ranged from 3 to 5 (i.e., 1 month to 6 months) in the misdemeanor assault - homosexual victim condition (M-Homo); 2 to 8 (i.e., probation to 5 years) in the misdemeanor assault - heterosexual victim condition (M-Hetero); 2 to 10 (i.e., probation to 10 
years) in the felony assault - homosexual victim condition (F-Homo); 3 to 8 (i.e., 1 month to 5 years) in the felony assault - heterosexual victim condition (F-Hetero); 5 to 14 (i.e, 6 months to life) in the attempted murder - homosexual victim condition (AM-Homo); and 5 to 14 (i.e, 6 months to life) in the attempted murder - heterosexual victim condition (AM-Hetero).

The obtained score ranges on the PPBS were as follows: 64 to 91 in the M-Homo condition ( $\bar{X}=78.23, S D=7.63)$; 61 to 91 in the M-Hetero condition ( $\bar{X}=73.92, S D=8.09$ ); 32 to 90 in the F-Homo condition ( $\bar{X}=74.92, S D=15.22$ ); 67 to 98 in the F-Hetero condition ( $\bar{X}=82.00, S D=10.03) ; 75$ to 90 in the AM-Homo condition $(\bar{X}=82.62, S D=4.39)$; and 62 to 98 in the AM-Hetero condition ( $\bar{X}=84.31, S D=10.23)$. The obtained scores on the PVBS ranged from 14 to 33 in the M-Homo condition ( $\bar{X}=23.54, S D=6.05$ ); 14 to 47 in the MHetero condition ( $\bar{X}=29.08, S D=9.22) ; 20$ to 68 in the F-Homo condition $(\bar{X}=34.85, S D=$ 16.14); 14 to 53 in the F-Hetero condition ( $\bar{X}=33.08, S D=11.84$ ); 15 to 53 in the AM-Homo condition ( $\bar{X}=28.31, S D=9.69)$; and 14 to 42 in the AM-Hetero condition ( $\bar{X}=28.38, S D=$ 8.18). Finally, the obtained score ranges on the MHS are as follows: 17 to 46 in the M-Homo condition $(\bar{X}=33.62, S D=8.90) ; 18$ to 45 in the M-Hetero condition $(\bar{X}=33.92, S D=7.83)$; 28 to 54 in the F-Homo condition ( $\bar{X}=38.54, S D=7.63$ ); 26 to 47 in the F-Hetero condition ( $\bar{X}=35.54, S D=8.00$ ); 29 to 56 in the AM-Homo condition ( $\bar{X}=38.08, S D=8.79$ ); and 18 to 57 in the AM-Hetero condition ( $\bar{X}=35.77, S D=11.69)$.

In addition to these descriptive statistics, reliability statistics were run on the PPBS, PVBS, and the MHS to determine whether these measures displayed comparable reliability to those reported by the author of the measures. The following Cronbach's alphas were obtained in 
this pilot study: 0.80 for the PPBS; 0.83 for the PVBS; and 0.84 for the MHS. Although these four measures displayed adequate variability in their responses and continued to show good reliability in this pilot study, a ceiling effect was obtained on the AFS. Seventy of the participants indicated that they perceived the crime as being entirely the perpetrator's fault (an assigned value of 7) and the remaining eight participants endorsed a value of 6 , indicating a minimal decrease in responsibility. Due to this lack of variability in responses, the researcher chose not to utilize this measure in the current study as it was not perceived to be a strong measure of this variable.

\section{Qualitative data.}

Qualitative data was also obtained from the participants' completion of the feedback questionnaire. An examination of this qualitative data indicated participants had consistent difficulties with clarity associated with the PPBS and the PVBS. In particular, several participants noted they were unsure whether the word pair of "responsible/irresponsible" referred to the applied case or to the defendant/victim's general character. As a result of this feedback, a brief statement was added to each of these measures to ensure clarity of this item. With regard to discomfort related to participation in the study, only three participants endorsed having experienced discomfort and in all cases it was related to the discussion of homosexual individuals in general (e.g., "The whole discussion of gay people," "It makes me slightly uncomfortable to think about the deserved rights of gays"). Due to the low number of participants who provided this response and the nature of the study, no changes were made to the study based on the qualitative data obtained from the issue of discomfort. 


\section{Current Study}

\section{Sample.}

The original sample included 243 participants; however, one was omitted due to a large amount of missing data and four others were removed at their request following debriefing procedures, leaving a total of 238 participants. Participants ranged in age from 19 to 86 , with a mean age of 46.42 years $(S D=15.04)$ and a median age of 48 . The sample was composed of 95 men and 143 women, with $96.3 \%$ identifying as heterosexual. With regard to racial composition, $63 \%$ of participants were Caucasian $(n=150)$ and $32.8 \%$ were African-American $(n=78)$, with the remainder $4.1 \%$ being either Hispanic/Latino $(n=2)$, Asian-American $(n=1)$, Native American $(n=2)$, or mixed race $(n=5)$. Due to the small number of participants who were not either Caucasian or African-American $(n=10)$, the remainder of these participants were placed in one "Other" category for the purposes of statistical analyses involving race.

Additional demographic and historical information obtained from participants included religion, education, political ideology, history of jury service, history of criminal charges and convictions, and history of personal, familial, and friend victimization. For ease of review, demographic information pertaining to religion, education, and political ideology is provided in Tables 5, 6, and 7. When asked about their history of jury service, $30.7 \%$ of participants $(n=73)$ indicated they had served on a jury in the past; $46.6 \%$ having served on a criminal jury, $56.2 \%$ on a civil jury, and $10.9 \%$ on a grand jury. The majority of these participants only served on a jury once $(42.5 \%)$ or twice $(27.4 \%)$ before the current summons. Approximately $12 \%$ of participants $(n=28)$ had been charged with a crime in the past, with $85.7 \%$ who indicated that it was a misdemeanor offense and $10.7 \%$ a felony offense (one participant did not provide 
information on the type of charge). This number drops with criminal convictions $(n=18 ; 7.6 \%)$ and only one of those convictions was for a felony offense.

Table 5

Demographics - Religion

\begin{tabular}{lcc}
\hline & $n$ & $\begin{array}{c}\text { Percent of } \\
\text { Sample }\end{array}$ \\
\hline Baptist & 137 & 57.6 \\
Protestant & 36 & 15.1 \\
Other & 19 & 7.9 \\
Catholic & 15 & 6.3 \\
Non-denominational & 10 & 4.2 \\
None & 10 & 4.2 \\
Methodist & 7 & 2.9 \\
Presbyterian & 1 & 0.4 \\
Muslim & 1 & 0.4 \\
Jewish & 1 & 0.4 \\
Mormon & 0 & 0 \\
\hline
\end{tabular}


Table 6

Demographics - Education

\begin{tabular}{lcc}
\hline & $n$ & $\begin{array}{c}\text { Percent of } \\
\text { Sample }\end{array}$ \\
\hline Some college & 97 & 40.8 \\
High school diploma & 69 & 29.0 \\
Bachelor's Degree & 41 & 17.2 \\
Master's Degree & 18 & 7.6 \\
Some high school & 11 & 4.6 \\
No high school & 2 & 0.8 \\
Ph.D./M.D. & 0 & 0 \\
\hline
\end{tabular}

Table 7

Demographics - Political Ideology

\begin{tabular}{lcc}
\hline & $n$ & $\begin{array}{c}\text { Percent of } \\
\text { Sample }\end{array}$ \\
\hline $\begin{array}{l}\text { Moderate, "Middle of the } \\
\text { road" }\end{array}$ & 72 & 30.3 \\
Conservative & 63 & 26.5 \\
$\begin{array}{l}\text { Liberal } \\
\text { Slightly conservative }\end{array}$ & 26 & 10.9 \\
Slightly liberal & 25 & 10.5 \\
Extremely conservative & 16 & 6.7 \\
Extremely liberal & 7 & 6.7 \\
\hline
\end{tabular}


When asked questions about historical criminal victimization, $18.9 \%$ of participants indicated they had been a victim of crime at least one time in the past. Another $18.5 \%$ reported having a family member who had been a victim of crime. Finally, 39.7\% of participants noted having a friend who had previously been the victim of a crime. See Tables 8,9 , and 10 for a breakdown on the types of crime and frequency of victimization.

Table 8

Participants' Prior Victimization

\begin{tabular}{|c|c|c|}
\hline Description & $n$ & Percent of Sample \\
\hline \multicolumn{3}{|c|}{ Victim of crime in the past } \\
\hline Yes & 191 & 80.3 \\
\hline No & 45 & 18.9 \\
\hline \multicolumn{3}{|c|}{ Type of Crime } \\
\hline Robbery/Theft/Burglary & 34 & 14.3 \\
\hline Assault & 8 & 3.4 \\
\hline Vandalism & 1 & 0.4 \\
\hline Sexual Assault as a Child & 1 & 0.4 \\
\hline Hit and Run & 1 & 0.4 \\
\hline Domestic Violence & 1 & 0.4 \\
\hline \multicolumn{3}{|c|}{ Number of Times } \\
\hline One & 28 & 11.8 \\
\hline Two & 10 & 4.2 \\
\hline Three & 3 & 1.3 \\
\hline Five & 1 & 0.4 \\
\hline Ten & 1 & 0.4 \\
\hline Thirteen & 1 & 0.4 \\
\hline
\end{tabular}


Table 9

Participant Family Victimization

\begin{tabular}{|c|c|c|}
\hline Description & $N$ & Percent of Sample \\
\hline \multicolumn{3}{|c|}{ Victim of crime in the past } \\
\hline Yes & 175 & 73.5 \\
\hline No & 44 & 18.5 \\
\hline \multicolumn{3}{|c|}{ Type of Crime } \\
\hline Robbery/Theft/Burglary & 17 & 7.1 \\
\hline Assault & 5 & 2.1 \\
\hline Sexual Assault & 4 & 1.7 \\
\hline Murder & 4 & 1.7 \\
\hline Attempted Murder & 2 & 0.8 \\
\hline Sexual assault as a child & 2 & 0.8 \\
\hline Drug related & 2 & 0.8 \\
\hline DUI & 2 & 0.8 \\
\hline Shooting victim & 1 & 0.4 \\
\hline Manslaughter & 1 & 0.4 \\
\hline Identity Theft & 1 & 0.4 \\
\hline Scams & 1 & 0.4 \\
\hline \multicolumn{3}{|c|}{ Number of Times } \\
\hline One & 27 & 11.3 \\
\hline Two & 10 & 4.2 \\
\hline Three & 5 & 2.1 \\
\hline Four & 1 & 0.4 \\
\hline Six & 1 & 0.4 \\
\hline
\end{tabular}


Table 10

Participant Friend Victimization

\begin{tabular}{lcc}
\hline \multicolumn{1}{c}{ Description } & $N$ & Percent of Sample \\
\hline \multicolumn{3}{c}{ Victim of crime in the past } \\
Yes & 188 & 78.9 \\
No & 31 & 13.0 \\
& & \\
& Type of Crime & \\
& & \\
Robbery/Theft/Burglary & 15 & 6.3 \\
Assault & 3 & 1.3 \\
Murder & 3 & 1.3 \\
Sexual Assault & 2 & 0.8 \\
Sexual Assault as a Child & 2 & 0.8 \\
& & \\
\hline
\end{tabular}

Number of Times

\begin{tabular}{lcc} 
One & 21 & 8.8 \\
Two & 2 & 0.8 \\
Three & 1 & 0.4 \\
\hline
\end{tabular}

Qualitative analyses.

An examination of the answers on the feedback questionnaire was completed to determine what aspects of the study may have been unclear to participants or made them feel uncomfortable. When asked about clarity of the study, only 11 responses were obtained. Eight of these responses pertained to questions about how to provide ratings on the PPBS and PVBS, with two indicating they requested further information from the researcher during the study to clarify. The other three participants felt there was not enough information about the crime or the individuals involved to be able to provide ratings on the included measures. When asked about 
discomfort related to participation in the study, 12 participants endorsed having experienced discomfort. The most common response $(n=5)$ was associated with the discussion of homosexuals and the assumption the study was associated with "gay rights." Responses included, "Felt like this is being used to promote 'hate' crime laws" and "Not my favorite subject. No, I'm not tolerant of this lifestyle." Two participants noted discomfort associated with being asked questions about their family and friends on the demographics questionnaire. Other responses ( $n=1$, respectively) included discomfort with having to make judgments on little information/a single incident, asking whether the participant had been convicted of a crime in the past, asking questions about the victim and defendant ("made my opinion personal"), "determining how long the sentence should be," and the MHS.

A question was also included on the demographics questionnaire to determine whether participants were able to decipher what the study was trying to examine. Of those who responded to this open-ended question, the most common response $(n=52)$ was that the study was looking at issues generally associated with homosexuals. For example, biases or prejudice based on sexual orientation, participants' views/attitudes toward homosexuality, "gay rights," and crimes committed against homosexual individuals. Some of the responses were associated more with the participant's opinion on rights for homosexual individuals rather than answering the question regarding what the study was examining. Examples of these responses included, "Homosexual rights - And I don't believe they should have any," "That some people are mean. That gays have rights and need rights," “Too much time and tax money spent on gay’s. Read your bible. May God bless you," and "Trying to find out what I feel for homosexual. It's wrong it says so in the good book. People need to start studying the bible a lot more." 
The next most common response $(n=50)$ was associated with participants' beliefs that the study was examining how a juror's personal opinions/viewpoints/experiences might influence the way they view the facts and individuals involved in the case and their ultimate decision. Of these 50 responses, only eight participants believed that the study was specifically looking at how a juror's views of homosexuality may impact their decision-making during a criminal trial. One example of these responses was, "Society's acceptance of homosexual men and the fact that a person's homosexuality affects the decision of the people on the jury. Instead of judging a person for their crime, people are inclined to remember that fact that a person is or is not homosexual." The other seven responses were: "The perception potential jurors might have based upon factors (gay) not related to the crime," "Views about homosexual and fairness in a trial regardless of feelings about homosexuals," "The effects that a person's personal views about gay rights and homosexuality might have on that person's decisions as a juror," "How gays are viewed by jurors if they are a victim of a crime," "How I feel about gay rights and whether they should receive the same trial if the crime happened to them and they were not gay," "If a juror should determine a person's sexuality be the cause of being attacked and the defendants' risks," and "The way a juror's morality determines ones fate on or someone's something (sexuality) even though they don't agree with that person's lifestyle."

\section{Exploratory analyses.}

Prior to examining the experimental factors in this study, a number of exploratory analyses were completed. Several univariate analyses (e.g., ANOVAs or simple linear regressions) were conducted to determine whether any variance in the dependent variables may be related to the obtained demographic and historical information of the participants. 
Preemptively determining these factors allowed for any differences to be controlled for in the analysis of experimental factors. The first set of univariate analyses was conducted on the Sentencing Recommendation Form. No significant differences on the Sentencing

Recommendation Form were found between participants based on any of the demographic and historical factors included in this study, or the participants' level of homonegativity (See Table 11 for full results).

Table 11

Exploratory Analyses on SRF

\begin{tabular}{lccccc}
\hline Demographics & $d f$ & Error $d f$ & $\mathrm{~F}$ & $p$ & $R^{2}$ \\
\hline Age $(\beta=-.02)$ & 1 & 231 & 2.37 & .13 & .01 \\
Sex & 1 & 231 & .10 & .75 & .000 \\
Race & 2 & 230 & .62 & .35 & .003 \\
Religion & 9 & 222 & 1.02 & .43 & .04 \\
Education $(\beta=.24)$ & 1 & 231 & 1.29 & .26 & .006 \\
Political Ideology $(\beta=.18)$ & 1 & 219 & 1.64 & .20 & .007 \\
Prior jury service & 1 & 232 & .58 & .45 & .002 \\
Charged with crime & 1 & 230 & 1.01 & .32 & .004 \\
Convicted of crime & 1 & 231 & .54 & .47 & .002 \\
Victim of crime & 1 & 229 & .002 & .97 & .000 \\
Family victim of crime & 1 & 213 & .000 & .99 & .000 \\
Friend victim of crime & 1 & 213 & 1.37 & .24 & .006 \\
MHS $(\beta=.005)$ & 1 & 224 & .04 & .85 & .000 \\
\hline
\end{tabular}


Several demographic and historical factors were found to be significantly related to participants' perceptions of perpetrator blame. A significant negative relation was found between participants' age and perceptions of perpetrator blame $(F[1,215]=4.39, \beta=-.13$, $p=.03$ ), such that higher levels of blame were assigned as participants became younger. A significant relation between race and perceptions of perpetrator blame was also found $(F[2,214]$ $=5.46, p=.005)$, such that Caucasian participants assigned higher amounts of blame to the perpetrator than African-American participants. The mean score for Caucasian participants was $76.61(S D=11.41)$ and the mean score for African-American participants was $70.16(S D=$ 16.41).

A significant relation was also found between participants' education level and perceptions of perpetrator blame $(F[1,215]=8.51, \beta=2.71, p=.004)$, such that perpetrator blame increased as the participants' level of education increased. No differences on perceptions of perpetrator blame were found to be associated with sex, religion, political ideology, history of jury service, history of criminal charges or convictions, or history of personal, familial, or friend victimization. In addition, no significant relation was found between homonegativity and perceptions of perpetrator blame (See Table 12 for full results).

Significant relations were also found between participants' perceptions of victim blame based on demographic and historical factors. There was a significant relation found between race and perceptions of victim blame $(F[2,211]=3.41, p=.04)$, such that African-American participants assigned significantly higher amounts of blame to victims across all conditions than did Caucasian participants. A significant relation was also found between participants' education and perceptions of victim blame $(F[1,212]=6.20, \beta=-3.12, p=.01)$, with victim 
blame decreasing as the participants' level of education increased. Additionally, those participants who had been a victim of a crime in the past or had a friend who was a victim of a crime assigned significantly less blame to the $\operatorname{victim}(F[1,210]=5.00, p=.02 ; F[1,195]=3.83$, $p=.05$, respectively) than those who had not been a victim or had a friend who was a victim. No significant differences were found between participants on perceptions of victim blame based on age, sex, religion, political ideology, history of jury service, history of criminal charges or convictions, or history of familial victimization. There was also no significant relation between homonegativity and perceptions of victim blame (See Table 13 for full results).

Additional exploratory univariate analyses were conducted to determine whether any of the demographic and historical variables were significantly related to participants' ratings on the Modern Homonegativity Scale (MHS). A significant relation between participants' sex and scores on the MHS was found $(F[1,226]=12.27, p=.001)$, such that males $(\bar{X}=43.62, S D=$ 7.32) showed higher levels of homonegativity than females $(\bar{X}=39.63, S D=9.07)$. There was also a significant relation between race and MHS scores $(F[2,225]=10.83, p<.001)$, which indicated African-American participants ( $\bar{X}=3.56, S D=8.34$ ) obtained lower homonegativity scores than Caucasian participants ( $\bar{X}=43.10, S D=8.31$ ). Due to these two significant results, an additional model was utilized which included both sex and race to determine whether these variables were accounting for unique amounts of variability in the MHS. Both the significant relations between race $(F[2,221]=8.69, p<.001)$ and $\operatorname{sex}(F[1,221]=6.51, p=.01)$ with MHS scores were maintained. However, no significant interaction was found between sex and race on MHS scores $(F[2,221]=.42, p=.66)$. 
Table 12

Exploratory Analyses on PPBS

\begin{tabular}{lccccc}
\hline Demographics & $d f$ & Error $d f$ & $\mathrm{~F}$ & $p$ & $R^{2}$ \\
\hline Age $(\beta=-1.31)$ & 1 & 215 & 4.39 & .03 & .02 \\
Sex & 1 & 215 & .07 & .79 & .000 \\
Race & 2 & 214 & 5.46 & .005 & .05 \\
Religion & 9 & 206 & 1.39 & .19 & .06 \\
Education $(\beta=2.71)$ & 1 & 215 & 8.51 & .004 & .19 \\
Political Ideology $(\beta=.74)$ & 1 & 203 & 1.37 & .24 & .007 \\
Prior jury service & 1 & 216 & .45 & .50 & .002 \\
Charged with crime & 1 & 214 & 1.09 & .29 & .005 \\
Convicted of crime & 1 & 215 & .73 & .39 & .003 \\
Victim of crime & 1 & 213 & 1.51 & .22 & .007 \\
Family victim of crime & 1 & 196 & .000 &. .99 & .000 \\
Friend victim of crime & 1 & 196 & .09 & .75 & .000 \\
MHS $(\beta=-.049)$ & 1 & 211 & .19 & .66 & .001 \\
\hline
\end{tabular}


Table 13

Exploratory Analyses on PVBS

\begin{tabular}{lccccc}
\hline Demographics & $d f$ & Error $d f$ & F & $p$ & $R^{2}$ \\
\hline Age $(\beta=.12)$ & 1 & 112 & 2.16 & .14 & .01 \\
Sex & 1 & 212 & 1.39 & .24 & .007 \\
Race & 2 & 211 & 3.41 & .04 & .03 \\
Religion & 9 & 204 & 1.30 & .24 & .05 \\
Education $(\beta=-3.12)$ & 1 & 212 & 6.20 & .01 & .03 \\
Political Ideology $(\beta=-.87)$ & 1 & 202 & 1.16 & .28 & .006 \\
Prior jury service & 1 & 213 & .79 & .37 & .004 \\
Charged with crime & 1 & 211 & .14 & .71 & .001 \\
Convicted of crime & 1 & 212 & .19 & .67 & .001 \\
Victim of crime & 1 & 210 & 5.00 & .02 & .02 \\
Family victim of crime & 1 & 195 & .09 & .75 & .000 \\
Friend victim of crime & 1 & 195 & 3.83 & .05 & .02 \\
MHS $(\beta=.22)$ & & 208 & 2.45 & .12 & .01 \\
\hline & & & & & \\
\hline
\end{tabular}

Participants' political ideology had a significant impact on MHS scores $(F[1,214]=$ $4.15, \beta=1.70, p<.001)$, such that MHS scores increased as participants identified as more conservative. In addition, participants' history of jury service had a significant impact on their scores of homonegativity $(F[1,227]=5.41, p=.02)$, indicating those who served on a jury in the past obtained higher scores on the MHS than those participants with no prior jury experience. No significant differences on homonegativity were observed based on age, religion, education, 
history of criminal charges or convictions, or history of personal, familial, or friend victimization (See Table 14 for full results).

Table 14

Exploratory Analyses on MHS

\begin{tabular}{lccccc}
\hline Demographics & $d f$ & Error $d f$ & F & $p$ & $R^{2}$ \\
\hline Age $(\beta=.04)$ & 1 & 226 & 1.23 & .27 & .005 \\
Sex & 1 & 226 & 12.27 & .001 & .05 \\
Race & 2 & 225 & 10.83 & $<.001$ & .09 \\
Religion & 9 & 217 & .63 & .77 & .03 \\
Education $(\beta=-.99)$ & 1 & 226 & 3.09 & .08 & .01 \\
Political Ideology $(\beta=1.70)$ & 1 & 214 & 4.15 & $<.001$ & .09 \\
Prior jury service & 1 & 227 & 5.41 & .02 & .02 \\
Charged with crime & 1 & 225 & .09 & .77 & .000 \\
Convicted of crime & 1 & 226 & .15 & .70 & .001 \\
Victim of crime & 1 & 224 & .45 & .51 & .002 \\
Family victim of crime & 1 & 207 & .05 & .82 & .000 \\
Friend victim of crime & 1 & 207 & .69 & .41 & .003 \\
\hline
\end{tabular}

A set of correlation analyses were run to determine whether there were any unexpected relations found between the included measures (i.e., the SRF, PPBS, PVBS, and the MHS). No unexpected relations were found (see Table 15); however, a significant relation was found between scores obtained on the Perceptions of Perpetrator Blame Scale (PPBS) and Perceptions of Victim Blame Scale (PVBS). It was expected these concepts would have a negative 
correlation since it would be difficult to place the same level of blame on both the perpetrator and victim of a crime. Completing a correlation analysis helped to ensure this theoretical difference was obtained in the current sample. As expected, a significant negative correlation was found $(r=-.547, t=-9.54, p<.001)$, which indicated levels of perpetrator blame increased when levels of victim blame decreased. This significant correlation shows that these two constructs were related, but continued to measure different variables.

Table 15

Correlation Analyses of Measures

\begin{tabular}{lccc}
\hline Correlated Measures & $r$ & $t$ & $p$ \\
\hline SRF - PPBS & .073 & 1.07 & .29 \\
SRF - PVBS & .019 & .28 & .78 \\
SRF - MHS & .013 & .19 & .85 \\
PPBS - PVBS & -.547 & -9.54 & $<.001$ \\
PPBS - MHS & -.031 & .45 & .66 \\
PVBS - MHS & .108 & 1.57 & .12 \\
\hline
\end{tabular}

Factors influencing assignment of punishment.

It was hypothesized that jurors would assign higher punishments to the perpetrator when the victim was heterosexual, but these differences would only be significant for those individuals high in homonegativity and most pronounced in the least severe crime. A single, mixed General Linear Model (GLM) was utilized to measure the relations between severity of crime, victim sexual orientation, and homonegativity on the assignment of punishment. This model was utilized due to the inclusion of both categorical independent variables (i.e., severity of crime and 
victim sexual orientation) and a continuous moderating variable (i.e., homonegativity). All assumptions of parametric statistics were checked by examining the residuals for normality and homoscedasticity.

Results showed the severity of crime was able to explain a significant and unique amount of variability in assignment of punishment $(F[2,214=4.61, p=.01)$, above and beyond victim sexual orientation and homonegativity. Examination of the estimated marginal means indicated an increase in the amount of punishment assigned as the crime became more severe (See Table 15). Despite obtaining this expected outcome, no main effect of victim sexual orientation on assignment of punishment was found $(F[1,214]=2.46, p=.12)$. This signified that there was no difference observed between the amount of punishment assigned based on whether the victim was heterosexual (perceived as homosexual) or homosexual. A separate simple linear regression was run to determine whether homonegativity had an independent impact on the assignment of punishment; however, no significant relation was found $(F[1,224]=.04, \beta=.005, p=.85)$. Table 16

Case Type Means by Group on SRF

\begin{tabular}{lcccc}
\hline Group & $n$ & $\bar{X}$ & $S D$ & $s^{2}$ \\
\hline Misdemeanor Assault & 76 & 4.71 & 2.04 & 4.16 \\
Felony Assault & 76 & 5.78 & 1.75 & 3.06 \\
Attempted Murder & 82 & 9.96 & 3.02 & 9.12 \\
\hline
\end{tabular}

Examination of the interactions between the two experimental variables and the moderating variable was also conducted. No significant interactions were found between severity of crime and victim sexual orientation $(F[2,214]=.13, p=.88)$ or severity of crime and 
homonegativity $(\mathrm{F}[2,214]=1.63, p=.19)$ on assignment of punishment. Finally, the predicted three-way interaction between severity of crime, victim sexual orientation, and homonegativity on assignment of punishment was not obtained $(F[2,214=.05, p=.95)$.

Perceptions of perpetrator blame.

A single 3 X 2 analysis of covariance (ANCOVA) was performed to look at the potential relations between severity of crime and victim sexual orientation on perceptions of perpetrator blame. Since participants' age, race, and education were identified as having significant relations to perceptions of perpetrator blame during the initial exploratory analyses, these variables were entered into the model as covariates to control for the variance each of these variables may explain. In addition, the residuals of all parametric statistics associated with perpetrator blame were checked for normality and homoscedasticity.

A significant relation was found between the victim's sexual orientation and participants' perceptions of perpetrator blame $(F[1,208]=7.36, p=.007)$. An examination of the estimated marginal means indicated more blame was assigned to the perpetrator when the victim was homoosexual than when the victim was heterosexual (See Table 16). On the other hand, no significant relation was found between the severity of crime and participants' perceptions of perpetrator blame $(F[2,208]=.07, p=.93)$. There was also no significant interaction found between severity of crime and victim sexual orientation on perceptions of perpetrator blame $(F[2,208]=.14, p=.87)$.

Due to the significant relation found between the victim's sexual orientation and participants' perceptions of perpetrator blame, a new single, mixed GLM model was performed, which added homonegativity in the model as a moderating variable and also examined the 
interaction between the victim's sexual orientation and participants' level of homonegativity. The severity of crime was maintained in this analysis to account for any shared variance. After homonegativity was added into the model, the previously significant relation between victim sexual orientation and participants' perceptions of perpetrator blame was no longer significant $(F[1,197]=.40, p=.53)$. However, there was also no significant interaction between victim sexual orientation and homonegativity found on perceptions of perpetrator blame $(F[1,197]=$ $1.32, p=.25)$. In addition, no main effect of homonegativity was found $(F[1,197]=.10, p=$ $.75)$.

Table 17

Victim Sexual Orientation Means by Group on the PPBS

\begin{tabular}{lcccc}
\hline Group & $n$ & $\bar{X}$ & $S D$ & $s^{2}$ \\
\hline Heterosexual & 106 & 71.66 & 13.83 & 191.27 \\
Homosexual & 112 & 77.10 & 13.22 & 174.77 \\
\hline
\end{tabular}

Perceptions of victim blame.

A second 3 X 2 analysis of covariance (ANCOVA) was performed to look at the potential relations between severity of crime and victim sexual orientation on perceptions of victim blame. Similar to the last model, since participants' race, education, and history of personal and friend victimization were identified as having significant relations to perceptions of victim blame during the initial exploratory analyses, these variables were entered into the model as covariates to control for the variance each of these variables may explain. Again, assumptions of normality and homoscedasticity were met. 
A significant relation was found between the severity of crime and participants' perceptions of victim blame $(F[2,187]=3.66, p=.03)$. An examination of the estimated marginal means indicated participants' assigned significantly lower amounts of blame to the victim when the crime was a misdemeanor assault as opposed to either a felony assault or attempted murder (See Table 17). There were no significant differences found between the felony assault and attempted murder conditions. In addition, no significant relation was found between the victim's sexual orientation and perceptions of victim blame $(F[1,187]=2.92, p=$ .09). There was also no significant interaction found between severity of crime and victim sexual orientation $(F[2,187]=.02, p=.99)$.

Table 18

Case Type Means by Group on the PVBS

\begin{tabular}{lcccc}
\hline Group & $n$ & $\bar{X}$ & $S D$ & $s^{2}$ \\
\hline Misdemeanor Assault & 69 & 33.38 & 15.16 & 229.83 \\
Felony Assault & 74 & 41.28 & 16.04 & 257.28 \\
Attempted Murder & 72 & 41.97 & 20.09 & 403.61 \\
\hline
\end{tabular}

Similar to perceptions of perpetrator blame, a new single, mixed GLM model was run which added homonegativity in as a moderating variable between severity of crime and perceptions of victim blame. The addition of homonegativity in this model led to loss of the previously significant relation between severity of crime and perceptions of victim blame $(F[2$, $176]=.23, p=.79)$. However, there was a main effect of homonegativity found $(F[1,176]=$ $5.08, p=.03$ ), such that higher levels of homonegativity led to higher perceptions of victim 
blame. Despite this main effect, no significant interaction of severity of crime and homonegativity on perceptions of victim blame were found $(F[2,176]=.02, p=.99)$. 


\section{DISCUSSION}

There continues to be controversy surrounding the inclusion of sexual orientation in the definition of hate crimes in the United States. Despite research showing these crimes are underreported (Herek, Gillis, \& Cogan, 2002; Dunbar, 2006), there is very limited research focused on how these crimes are viewed within the criminal justice setting. Specifically, there is a void in the research with regard to examining whether ingroup/outgroup biases supported by research in other settings extends to the outcomes of sexual orientation-based (SO) hate crimes in the courtroom. In fact, very few courtroom-based studies have even looked at attributions of blame in sexual orientation-based hate crimes (Lyons, 2006; Cramer et al., 2008; Rayburn \& Davison, 2002; Rayburn, Mendoza, \& Davison, 2003; Saucier et al., 2006). Whether these fears of potential retribution from victims' publicly revealing their sexuality are justified will remain unclear without further exploration into the factors that influence the outcomes and attributions of blame in these circumstances.

The current study sought to provide some insight into factors that influence sentencing outcomes and attributions of blame in SO hate crimes. Specifically, the focus was to include two factors previously ignored in the limited research on SO hate crimes: (1) the severity of the crime and (2) the victim's sexual orientation. Although the federal definition of a hate crime includes the caveat that the victim is chosen due to their "actual or perceived" membership in a group (United States Congress, 1994), the distinction between these labels has been widely 
overlooked in hate crime research. The current study aimed to examine this distinction and to extend previous research on the influence of severity of crime and homonegativity to jury decision-making in SO hate crimes. In addition, utilization of a representative subject pool of eligible jurors was thought to provide more ecological validity than previous studies in which only "mock jurors" (i.e., undergraduate students) were utilized.

\section{General Findings: Assignment of Punishment}

Previous research associated with SO hate crimes has not looked at factors that influence the assignment of punishment to the perpetrator. The sentencing structure of the criminal justice system is set up to assign higher levels of punishment to more severe crimes and it is believed jury pools involved in the criminal justice process have an understanding of this general structure. The results of the current study are consistent with this belief and show jurors will generalize this pattern to SO hate crimes. The participants assigned significantly higher punishments to each level of crime as the severity of the crime increased; therefore, the least amount of punishment was given to the perpetrator who committed a misdemeanor assault and the most was given to the perpetrator who committed attempted murder. Although this pattern was expected, the goal of the current study was to determine whether other factors have an influence on this relation.

Specifically, it was hypothesized that the distinction between actual or perceived group membership (i.e., victim sexual orientation) and a participants' level of homonegativity would impact this relation. However, the results did not support this hypothesis. Neither the victim's sexual orientation nor the participants' level of homonegativity had a significant impact on the 
amount of punishment assigned. In addition, these factors did not moderate the relation between the severity of the crime and assigned punishment.

The results of prior research associated with ingroup/outgroup and attribution theories may help to provide clarity regarding the lack of results in the current study. According to the similarity-leniency hypothesis (Kerr, Hymes, Anderson, \& Weathers, 1995; Abwender \& Hough, 2001; Sommors \& Ellsworth, 2000; Van Proojien, 2006; Wuensch, Campbell, Kesler, \& Moore, 2002) differences should have been observed based on the participants' potential perceived similarity to the heterosexual victim (as the far majority of participants were heterosexual), such that higher punishments would be given to the perpetrator when the victim was heterosexual. However, it may be that the "Black Sheep Effect" (Marques, Yzerbyt, \& Leyens, 1988; Marques \& Yzerbyt, 1988) provides a better basis for understanding the lack of significant results. According to this theory, ingroup members are viewed more severely (in either a positive or negative manner) than outgroup members when the ingroup member behaved in a manner inconsistent with the group norm. In this study, the "Black Sheep Effect" is demonstrated by a harsher view of the heterosexual victim despite the commonality in sexual orientation between the heterosexual victim and the majority of participants. The "Black Sheep Effect" would explain that this harsher view may have come from the heterosexual victim being deemed unlikeable in some way, potentially due to their proximity to a bar frequented by homosexuals. In addition, Van Prooijen (2006) acknowledged that the certainty of a defendant's guilt can lead to more retributive reactions to ingroup members regardless of the individual's dissimilarity to the victim in the case. Since each of the vignettes included in this study already established clear 
guilt of the perpetrator, this could have had a negating effect on the influence of the victim's sexual orientation on the assignment of punishment.

\section{General Findings: Attributions of Blame}

One goal of the current study was to provide a greater understanding of how the severity of a crime and the victim's sexual orientation impact attributions of blame and whether homonegativity influences these relations. As a reminder, a positive relation between the severity of crime and perpetrator blame, and a negative relation between severity of crime and victim blame, were hypothesized based on defensive attribution theory (Shaver, 1970; Walster, 1966). The current study found participants' assigned significantly lower levels of blame to the victim when the crime was a misdemeanor assault; however, this relation became non-significant when homonegativity was entered into the model. No relation between severity of crime and perpetrator blame were found. In addition, despite the initial significant main effect of severity of crime on victim blame, no significant interaction between severity of crime and homonegativity was found on victim blame. However, a significant main effect of homonegativity on victim blame was found, which indicated higher levels of victim blame as levels of homonegativity increased.

The basis of defensive attribution theory (Shaver, 1970; Walster, 1966) is that more responsibility is assigned to individuals in situations when the results of their action or inaction are associated with severe consequences. In line with prior research, the current results do not support the relevance of the defensive attribution theory since no main effect of severity of crime was found once homonegativity was entered into the model. In fact, the results of prior research (Burger, 1981; Chaikin \& Darley, 1973; Debotys \& Dasgupta, 1987; Herzog, 2008; Robbennolt, 
2000; Shaver, 1970; Shaw \& McMartin, 1977) suggest defensive attributions are evident in situations where the individual relates strongly to the situation itself or the individuals involved in the situation. Since past research has shown higher levels of homonegativity in individuals who live in the southern United States (Sherrod \& Nardi, 1998), it is possible the participants in this sample had a difficult time relating to the situation or the individuals in the vignettes as their exposure to homosexual bars may be limited. In addition, results of the Robbennolt (2000) meta analysis on defensive attribution theory noted stronger correlations between outcome severity and attributions of blame when more realistic simulations (i.e., audiotape or videotape) and actual jurors/adult participants were utilized. Despite use of a representative jury sample, the limited information provided in the written vignettes utilized may have impacted the ability to gain a true measurement of the potential relations between severity of crime and attributions of blame. It is possible that if more realistic simulations, such as audiotape or videotape of the crime or testimony, were utilized, a better measure of these relations could have been obtained.

Based on ingroup/outgroup theories, it was hypothesized that the victim's sexual orientation would have a significant impact on attributions of blame. Specifically, it was hypothesized that higher amounts of blame would be attributed to the perpetrator and lower amounts to the victim when the victim was heterosexual (perceived as homosexual). Though no main effect of victim sexual orientation on victim blame was found, a relation was found between victim sexual orientation and perpetrator blame. Results showed more blame was attributed to the perpetrator when the victim was homosexual.

Despite this initial significant main effect on perpetrator blame, the inclusion of homonegativity in the model led to loss of this effect. Similar to the relation between severity of 
crime and victim blame, there was still no significant interaction between victim sexual orientation and homonegativity; however, there was also no significant main effect of homonegativity. It appears there must be some shared variance of homonegativity with severity of crime and victim sexual orientation which contributed to the attribution of blame variables. Despite this shared variance, these variables are not interacting with each other to explain a significant amount of variance in the blame variables.

These results partially support the findings obtained by past ingroup/outgroup and attribution theories. Herzog (2008) showed less blame being assigned to a victim if they were similar to the observer and more blame when the victim is considered dissimilar. Since nearly all of the participants identified themselves as heterosexual, it is likely that they identified more to the perpetrator than the victim. Despite the victim being heterosexual in half the scenarios, it is possible their presence at a bar frequented by homosexuals may have caused those individuals to still be seen as dissimilar from the participants. In addition, as Herzog (2008) suggests, participants may have attributed blame to the heterosexual victim to allow them to feel that it would be less likely for them to be placed in a similar victimized position.

The lack of significant results associated with victim sexual orientation and victim blame could be associated with the range of responses achieved on the MHS. Lyons (2006) found that homosexual victims were generally blamed more often than heterosexual victims of crime and that less blame was only assigned to homosexual victims when the respondents had relatively pro-gay/lesbian attitudes. The majority of scores obtained on the MHS were in the middle range of possible scores, which suggests there may not have been enough pro-LGBT attitudes found in the current sample to detect this difference. 
One way to explain the results associated with victim sexual orientation and perpetrator blame and punishment outcome is through the use of Goffman's (1963) description of courtesy stigma or stigma-by-association. In the case of the current study, it is possible that the heterosexual victim was stigmatized or devalued by the participants because they were seen at an establishment frequented by homosexual individuals. The results of Sigelman, Howell, Cornell, Cutright, and Dewey (1991) supports this theory, as their results demonstrated that courtesy stigmatization was enhanced when the male in the study actively chose to room with a gay male. In addition, Neuberg, Smith, Hoffman, and Russell's (1994) study added that this effect persisted in their study even when the heterosexual male in the study was similar to the participant. Based on the wording of the current vignettes, these assumptions hold true as it is possible the participants believed that the heterosexual victim chose to go to a bar "frequented by gay men" even though there is no reference to the victim having knowledge of this fact prior to reaching the bar. In addition to theories of courtesy stigmatization, Fiske and Taylor's (1991) definition of defensive attribution (different than the DAT views already discussed) allows for the idea that individuals may distance themselves from similar victims to avoid the idea that something similar may happen to them. In this case, Fiske and Taylor's definition would assume increased blame to the heterosexual victim occurred as a way for the participants to believe they would be able to avoid a similar situation.

Finally, the lack of homonegativity acting as a moderator in most of the hypothesized relations contradicts all the previous research involving SO hate crimes and homonegativity (Cramer et al, 2008; Rayburn \& Davison, 2002; Rayburn, Davison, \& Mendoza, 2003). Each of these prior research studies provided evidence that individuals with higher levels of 
homonegativity attributed more blame to hate crime victims and less blame to hate crime perpetrators. The current results are somewhat consistent with this outcome, since higher levels of homonegativity were significantly related to increase blame for the victim; however, no significant relation between homonegativity and perpetrator blame was found. The only difference between these studies and the current study, which might account for this disparity, is the current study utilized a representative sample as opposed to an undergraduate sample, potentially leading to differences in the distributions of these scores. It is also possible there were not enough participants who scored in the higher and/or lower range of scores on homonegativity, which would have impacted the ability to obtain a significant effect.

\section{Limitations of the Current Research}

The results of the current study helped to begin delving into research on alternative factors influencing jury decision-making in sexual orientation-based hate crimes. However, the results obtained did not match with what was hypothesized, which could be due to a number of limitations. The first of these limitations is that the current study utilized a brief survey to ensure it would fit into the time constraints presented as the result of utilizing a representative jury sample. Due to these constraints, the written vignettes could only provide very brief, concise information pertaining to the crime. Since each of the outcome measures were based on the information presented in these vignettes, the limited information likely made it difficult to obtain a real world view of how these factors may have influenced jury decision-making.

Similarly, the brief nature of this study makes it likely that only immediate cognitions and schemas were triggered in the participants. It is likely that these immediate cognitions/schemas might be challenged further by the more varied, widespread information 
provided through an actual trial. Despite this limitation, recognition of these immediate cognitions can also be important as it is more likely these cognitions can be identified during the jury selection process and can provide insight into the potential impact of these cognitions on the trial outcome.

Another limitation of the current study was the restricted location of the sample. All participants were obtained from the southern United States, which past research has shown to be an area with higher levels of conservatism and homonegativity (Sherrod \& Nardi, 1998).

Despite the possibility of this restricted sample lowering the ecological validity of the study, Jefferson County (where many of the participants were recruited) is an urban county with a population comprised of individuals both raised in the southern United States, as well as many other parts of the country. Since no specific questions were asked of the participants regarding where they were reared, it is impossible to determine whether this sample was truly restricted or may be more representative than appears on the surface.

If the current sample was restricted to individuals who were raised in the southern United States, it is possible this restricted sample influenced the range of responses on measures such as the Modern Homonegativity Scale (MHS). However, examination of the distribution of scores on the MHS produced a normal curve (See Figure 1), instead of the skewed curve that may be expected if biases were present in the majority of the respondents. The presentation order of the measures included in the study may provide another potential explanation for the lack of strong polarity on the MHS. The MHS was presented at the end of all of the experimental measures in an effort to reduce the possibility that the obvious nature of the measure would influence the participants' responses to the vignettes and associated measures. However, it is possible that 
presenting the vignette and the PPBS/PVBS prior to the MHS could have led to participants' tempering their responses on the MHS to appear less biased.

Figure 1

Distribution of Scores on the MHS

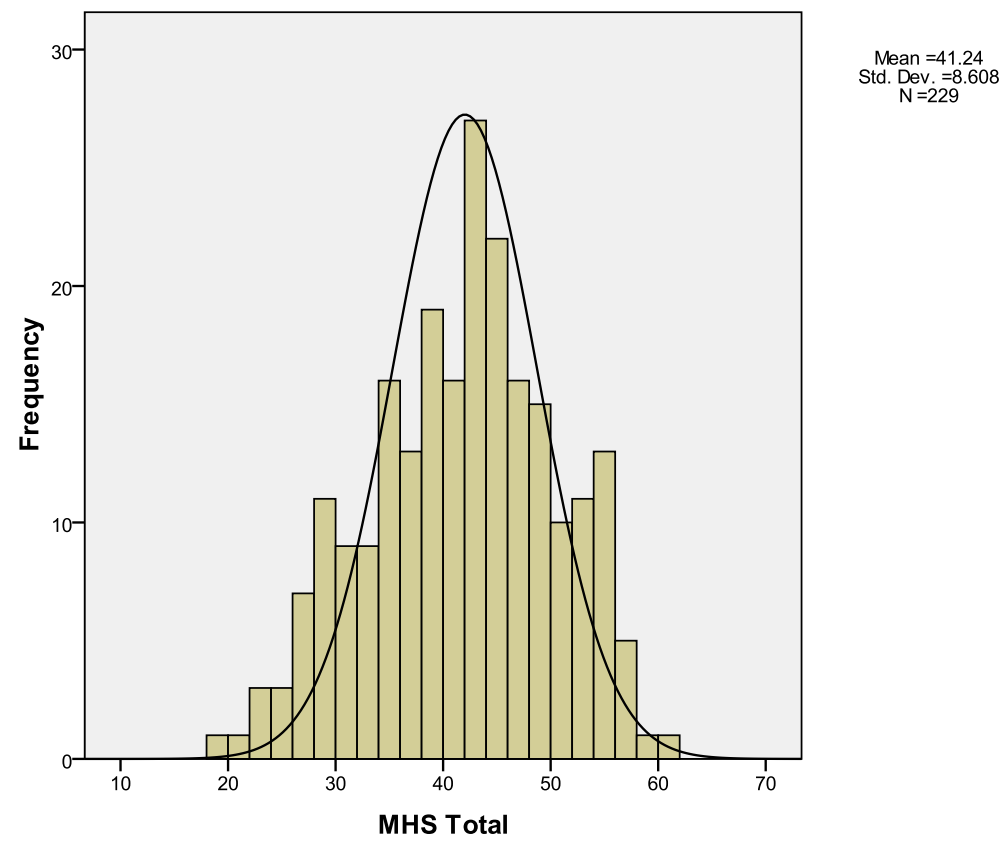

Finally, there is also the possibility that a social desirability bias may have been present. Although inclusion of a social desirability measure was considered, the additional time it would have added to the research battery led to a decision to exclude it from the study. There was concern that the obvious nature of social desirability measures could lead the participants to trigger additional schemas and result in changes being made (in a more socially desirable way) to previously provided answers. In addition, examination of responses on the MHS, which is the most likely measure to be effected by social desirability, showed that participants provided a 
wide range of responses. This indicates that a social desirability bias may not have been present, or if present, may not have had a significant impact on the results.

\section{Implications for Future Research and Practice}

The results of this study have begun to broaden the knowledge base in the area of verdict recommendations in trials of SO hate crimes and added to the limited research in this area. It was first identified study to utilize a representative jury sample, to look at factors influencing assignment of punishment in SO hate crimes, and to look at whether there are any relations between severity of crime and attributions of blame in SO hate crimes. In addition, it is the first known study to have examined differences between actual and perceived group membership in any type of hate crime research. The results provide some limited support for the idea that severity of crime and victim sexual orientation may impact attributions of blame, which is important to recognize when determining what factors may play a significant role in trials of SO hate crimes.

The knowledge gained from this study could be used by counsel during initial questioning of jurors ("voir dire") to assist in jury selection. "Voir dire" generally refers to the process by which prospective jurors are questioned about their backgrounds and potential biases before being chosen to sit on a jury. In general, selected jurors are expected to be unbiased and hold no preconceived notions with regard to guilt or innocence. The voir dire process allows both the prosecution and defense attorney to challenge any jurors they feel may hold any biases or preconceived notions about the individuals or the circumstances involved in the case. Further research on any biases that may influence the outcomes in criminal trials can assist attorneys in making more informed decisions during the voir dire process. The current study provides 
additional support for Sherrod and Nardi's (1998) belief that identifying homophobic jurors is important, particularly since this attitude has been shown to have a significant impact on verdicts in criminal trials (Hill, 2000).

The current study also has several implications for practical applications, particularly in the realm of trial consultation work. One of the major criticisms of mock jury research is that the results lack ecological validity. The use of a representative jury sample in this study helped to provide stronger ecological validity to the observed factors than prior research. Recognizing the role a victim's sexual orientation or the severity of the crime can play in how jurors perceive perpetrator and victim blame may assist jury consultants in conceptualizing how to approach trials that involve SO hate crimes. Therefore, the results may help provide consultants with another means for choosing potential jurors and an informed way of conceptualizing and anticipating the outcome of these trials.

Recognition during the voir dire process of how a victim's sexual orientation or the severity of crime might impact juror decision-making may assist in increasing attempts at due process and obtaining justice for victims of these crimes. In addition, identification of biases in trials of SO hate crimes will hopefully provide further support for the need to include sexual orientation in all state definitions of hate crimes. Hopefully the combination of recognizing these biases early and increasing the inclusion of sexual orientation will provide victims of these crimes with the strength to report these crimes and the willingness to move forward with prosecution. 


\section{REFERENCES}

Abwender, D. A., \& Hough, K. (2001). Interactive effects of characteristics of defendants and mock juror on U. S. participants' judgment and sentencing recommendation. Journal of Social Psychology, 141, 603-615.

Altemeyer, B. (1988). Enemies of freedom: Understanding right-wing authoritarianism. San Francisco, CA: Jossey-Bass Publishers.

Altemeyer, B. (1996). The authoritarian specter. Cambridge, MA: Harvard University Press.

Anti-Defamation League. (2008). Anti-defamation league state hate crime statutory provisions. Retrieved September 10, 2008, from http://www.adl.org/99hatecrime/state_hate_crime_laws.pdf.

Burger, J. M. (1981). Motivational biases in the attribution of responsibility for an accident: A meta-analysis of the defensive-attribution hypothesis. Psychological Bulletin, 90, 496512.

Chaikin, A. L., \& Darley, J. M. (1973). Victim or perpetrator? Defensive attribution of responsibility and the need for order and justice. Journal of Personality and Social Psychology, 25, 268-275.

Cohen, J. (1992). A power primer. Psychological Bulletin, 112, 155-159.

Cowan, G., Heiple, B., Marquez, C., Khatchadourian, D., \& McNevin, M. (2005). Heterosexuals' toward hate crimes and hate speech against gays and lesbians: Old-fashioned and modern heterosexism. Journal of Homosexuality, 49, 67-82.

Cramer, R. J., Wakeman, E. E., Mohr, J. J., Chandler, J. F., Griffin, M. P., \& Brodsky, S. L. (2008). Hate crimes on trial: Judgments about violent crime against gay men. Manuscript submitted for publication.

Debotys, R. J., \& Dasgupta, B. (1987). Attribution of responsibility and crime seriousness. The Journal of Psychology, 121, 607-613.

Dunbar, E. (2006). Race, gender, and sexual orientation in hate crime victimization: Identity politics or identity risk? Violence and Victims, 21, 323-337. 
Fiske, F. D., \& Taylor, S. E. (1991). Social cognition (2 $2^{\text {nd }} e d$.). New York, NY: McGraw-Hill.

Garnets, L., Herek, G. M., \& Levy, B. (1990). Violence and victimization of lesbians and gay men: Mental health consequences. Journal of Interpersonal Violence, 5, 366-383.

Goffman, E. (1963). Stigma: Notes on the management of spoiled identity. Englewood Cliffs, NJ: Prentice-Hall.

Gold, A. R., Landerman, P. G., \& Bullock, K. W. (1977). Reactions to victims of crime: Sympathy, defensive attribution, and the just world. Social Behavior and Personality, 5, 295-304.

Herek, G. M. (2000). The psychology of sexual prejudice. Current Directions in Psychological Science, 9, 19-22.

Herek, G. M., Gillis, J. R., Cogan, J. C., \& Glunt, E. K. (1997). Hate crime victimization among lesbian, gay, and bisexual adults. Journal of Interpersonal Violence, 12, 195-215.

Herek, G. M., Gillis, J. R., \& Cogan, J. C. (1999). Psychological sequelae of hate crime victimization among lesbian, gay, and bisexual adults. Journal of Consulting and Clinical Psychology, 67, 945-951.

Herek, G. M., Gillis, J. R., \& Cogan, J. C. (2002). Victim experiences in hate crimes based on sexual orientation. Journal of Social Issues, 58(2), 313-339.

Herzog, S. (2008). An attitudinal explanation of biases in the criminal justice system: An empirical testing of defensive attribution theory. Crime and Delinquency, 54, 457481.

Hill, J. M. (2000). The effects of sexual orientation in the courtroom: A double standard. Journal of Homosexuality, 39, 93-111.

Kerr, N. L., Hymes, R. W., Anderson, A. B., \& Weathers, J. E. (1995). Defendant-juror similarity and mock juror judgment. Law and Human Behavior, 19, 545-568.

Lipsey, M. W. (1990). Design sensitivity. Newbury Park, CA: Sage.

Lyons, C. J. (2006). Stigma or Sympathy? Attributions of fault to hate crime victims and offenders. Social Psychology Quarterly, 69, 39-59.

Marques, J.M. \& Yzerbyt, V.Y. (1988). The black sheep effect: Judgmental extremity towards ingroup members in inter-and intra-group situations. European Journal of Social Psychology, 18, 287-292. 
Marques, J.M., Yzerbyt, V.Y., \& Leyens, J-P. (1988). The "Black Sheep Effect": Extremity of judgments towards ingroup members as a function of groupidentification. European Journal of Social Psychology, 18, 1-16.

McDevitt, J., Levin, J., \& Bennett, S. (2002). Hate crime offenders: An expanded typology. Journal of Social Issues, 58, 303-317.

Morrison, M. A., \& Morrison, T.G. (2002). Development and validation of a scalemeasuring modern prejudice toward gay men and lesbian women. Journal of Homosexuality, 43, 1537.

Neuberg, S. L., Smith, D. M., Hoffman, J. C., \& Russell, F. J. (1994). When we observe stigmatized and "normal" individuals interaction: Stigma by association. Personality and Social Psychology Bulletin, 20, 196-209.

Phillips, D. M. (1985). Defensive attribution of responsibility in juridic decisions. Journal of Applied Social Psychology, 15, 483-501.

Rayburn, N. R., \& Davison, G. C. (2002). Articulated thoughts about antigay hate crimes. Cognitive Therapy and Research, 26, 431-447.

Rayburn, N. R., Mendoza, M., \& Davison, G. C. (2003). Bystanders' perceptions of victims and perpetrators of hate crimes. Journal of Interpersonal Violence, 18, 1055-1074.

Robbennolt, J. K. (2000). Outcome severity and judgments of "responsibility": A meta analytic review. Journal of Applied Social Psychology, 30, 2575-2609.

Saucier, D. A., Brown, T. L., Mitchell, R. C., \& Cawman, A. J. (2006). Effects of victims' characteristics on attitudes toward hate crimes. Journal of Interpersonal Violence, 21, 890-909.

Shaver, K. G. (1970). Defensive attribution: Effects of severity and relevance on the responsibility assigned for an accident. Journal of Personality and Social Psychology, 14, 101-113.

Shaw, J. I., \& McMartin, J. A. (1977). Personal and situational determinants of attribution of responsibility for an accident. Human Relations, 30, 95-107.

Sherrod, D., \& Nardi, P. M. (1998). Homophobia in the courtroom: An assessment of biases against gay men and lesbians in a multiethnic sample of potential jurors. In Stigma and Sexual Orientation: Understanding Prejudice against Lesbians, Gay Men, and Bisexuals. Herek, G. M. (Ed.). Thousand Oaks: Sage Publications, Inc. 
Sigelman, C. K., Howell, J. L., Cornell, D. P., Cutright, J. D., \& Dewey, J. C. (1991). Courtesy stigma: The social implications of associating with a gay person. The Journal of Social Psychology, 131, 45-56.

Sommors, S. R., \& Ellsworth, P. C. (2000). Race in the courtroom: Perceptions of guilt and dispositional attitudes. Personality and Social Psychology Bulletin, 26, 1367-1379.

Taylor, T. S., \& Hosch, H. M. (2004). An examination of jury verdicts for evidence of a similarity-leniency effect, an out-group punitiveness effect or a black sheep effect. Law and Human Behavior, 28, 587-598.

United States Congress. (1994). Violent crime control and law enforcement act of 1994. Retrieved April 19, 2008, from http://thomas.loc.gov/cgi-bin/query/z?c103:H.R.3355.ENR:

Van Prooijen, J.-W. (2006). Retributive reactions to suspected offenders: The importance of social categorizations and guilt probability. Personality and Social Psychology Bulletin, $32,715-726$.

Van Prooijen, J.-W., \& Lam, J. (2007). Retributive justice and social categorizations: The perceived fairness of punishment depends on intergroup status. European Journal of Social Psychology, 37, 1244-1255.

Vidmar, N., \& Crinklaw, L. D. (1974). Attributing responsibility for an accident: A methodological and conceptual critique. Canadian Journal of Behavioral Science, 6, 112130.

Walster, E. (1966). Assignment of responsibility for an accident. Journal of Personality and Social Psychology, 3, 73-79.

Wuensch, K. L., Campbell, M. W., Kesler, F. C., \& Moore, C. H. (2002). Racial bias in decisions made by mock jurors evaluating a case of sexual harassment. Journal of Social Psychology, 142, 587-600. 


\section{APPENDIX A}

\section{Demographic Questionnaire}

Please fill in all of the information below about yourself.

1. Age

2. Sex
$\square$ Male
$\square$ Female

3. Race (check all that apply)

$\square$ White/Caucasian

$\square$ Black/African-American

- Hispanic/Latino

$\square$ Asian-American

$\square$ Native American

B Biracial

$\square$ Other (specify)

4. Religion (check all that apply)
$\square$ Protestant
$\square$ Catholic
Baptist
a Jewish
a Mormon
a Muslim
$\square$ Other (specify)
a None

5. Education
ㄱo high school
$\square$ Some high school
- High school diploma
$\square$ Some college
B Bachelor's Degree
口 Master's Degree
$\square$ Ph.D./M.D.

6. Political Ideology (choose only one)

\section{- Extremely Liberal}



$\square$ Liberal
S Slightly Liberal
口 Moderate, "Middle of the Road"
- Slightly Conservative
$\square$ Conservative
Extremely Conservative

7. Sexual Orientation (choose only one)

$\square$ Heterosexual

$\square$ Homosexual

口 Bisexual

8. Have you ever served on a jury?

$\square$ No

$\square$ Yes. If yes, how many times?

What type(s) of trial(s)?

$\square$ Criminal

$\square$ Civil

$\square$ Other (specify)

9. Have you ever been charged with a crime?

$\square$ No

$\square$ Yes. If yes, please indicate the type(s) of crime.
$\bigcirc$ Misdemeanor
$\bigcirc$ Felony

10. Have you ever been convicted of a crime?
$\square$ No
$\bigcirc$ Misdemeanor
$\bigcirc$ Felony

$\square$ Yes. If yes, please indicate the type(s) of crime.

11. Have you ever been a victim of a crime?

\section{$\square$ No}

$\square$ Yes. If yes, please indicate the type(s) of crime and the number of times you have been a victim of that crime.

\begin{tabular}{|l|l|}
\hline Type of Crime & Number of times victimized \\
\hline & \\
\hline & \\
\hline & \\
\hline & \\
\hline & \\
\hline & \\
\hline
\end{tabular}


12. Has anyone in your family ever been a victim of a crime?

№

Yes. If yes, please indicate the type(s) of crime and the number of times a family member has been a victim of that crime.

\begin{tabular}{|l|l|}
\hline Type of Crime & Number of times victimized \\
\hline & \\
\hline & \\
\hline & \\
\hline & \\
\hline & \\
\hline & \\
\hline
\end{tabular}

13. Has a close friend ever been a victim of a crime?

№

Yes. If yes, please indicate the type(s) of crime and the number of times a friend has been a victim of that crime.

\begin{tabular}{|l|l|}
\hline Type of Crime & Number of times victimized \\
\hline & \\
\hline & \\
\hline & \\
\hline & \\
\hline & \\
\hline & \\
\hline
\end{tabular}

14. What do you believe this study is trying to examine? 


\section{APPENDIX B}

\section{Misdemeanor Assault Condition}

This is the sentencing phase of C. Johnson Case \#16279. Mr. Johnson has already been found guilty of a misdemeanor assault. The questions before you, the jury, relate to how long Mr. Johnson's sentence should be. Below are the details for the jury to consider. Mr. Williams and Mr. Johnson had never met prior to the night of the crime.

The Victim - Mr. Michael Williams

- 32-years-old

- Heterosexual/Homosexual male

- Job: Engineer for a power company

- Length of time at job: 9 years

- Active in his church.

- No prior arrests.

- No history of being violent.
The Defendant - Mr. Charles Johnson

- 35-years-old

- Heterosexual male

- Job: Engineer for a gas company

- Length of time at job: 12 years

- Active in his church.

- No prior arrests.

- No history of being violent.

Events of the crime: 1:25 a.m. on Friday, September 18, 2006

1. Mr. Williams was leaving a bar frequented by gay men. He crossed the street to go to his car and was confronted by Mr. Johnson.

2. Mr. Johnson asked Mr. Williams, "Did you just leave that faggot bar?"

3. Mr. Williams ignored the question and kept walking.

4. Mr. Johnson pushed Mr. Williams to the ground and hit him once in the face. He also cursed at Mr. Williams and called him a "faggot" and a "queer."

5. Mr. Williams got up, ran back to the bar, and called the police. Mr. Williams was not seriously hurt.

6. Mr. Johnson was arrested the next day and taken to the police station.

7. In a line-up, Mr. Williams identified Mr. Johnson as the man who attacked him.

Information from the trial:

- A neighbor of Mr. Johnson testified that Mr. Johnson often complained about gay people. This neighbor also stated that Mr. Johnson bragged about what he did after he returned home that night. He added that Mr. Johnson told him that "the fag deserved what he got." 


\section{APPENDIX C}

\section{Felony Assault Condition}

This is the sentencing phase of C. Johnson Case \#16279. Mr. Johnson has already been found guilty of a felony assault. The questions before you, the jury, relate to how long Mr. Johnson's sentence should be. Below are the details for the jury to consider. Mr. Williams and Mr. Johnson had never met prior to the night of the crime.

The Victim - Mr. Michael Williams

- 32-years-old

- Heterosexual/Homosexual male

- Job: Engineer for a power company

- Length of time at job: 9 years

- Active in his church.

- No prior arrests.

- No history of being violent.
The Defendant - Mr. Charles Johnson

- 35-years-old

- Heterosexual male

- Job: Engineer for a gas company

- Length of time at job: 12 years

- Active in his church.

- No prior arrests.

- No history of being violent.

Events of the crime: 1:25 a.m. on Friday, September 18, 2006

1. Mr. Williams was leaving a bar frequented by gay men. He crossed the street to go to his car and was confronted by Mr. Johnson.

2. Mr. Johnson asked Mr. Williams, "Did you just leave that faggot bar?"

3. Mr. Williams ignored the question and kept walking.

4. Mr. Johnson pushed Mr. Williams to the ground and hit him a number of times.

5. While hitting Mr. Williams, Mr. Johnson cursed at him. He also called him a "faggot" and a "queer."

6. Mr. Johnson then grabbed a rock and hit Mr. Williams in the head once with the rock and ran away.

7. Mr. Williams yelled for help.

8. A witness called the police. Mr. Williams was taken to the hospital and was released six hours later.

9. Mr. Johnson was arrested the next day and taken to the police station.

10. In a line-up, Mr. Williams identified Mr. Johnson as the man who attacked him.

Information from the trial:

- A neighbor of Mr. Johnson testified that Mr. Johnson often complained about gay people. This neighbor also stated that Mr. Johnson bragged about what he did after he returned home that night. He added that Mr. Johnson told him that "the fag deserved what he got." 


\section{APPENDIX D}

\section{Attempted Murder Condition}

This is the sentencing phase of C. Johnson Case \#16279. Mr. Johnson has already been found guilty of attempted murder. The questions before you, the jury, relate to how long Mr. Johnson's sentence should be. Below are the details for the jury to consider. Mr. Williams and Mr. Johnson had never met prior to the night of the crime.

The Victim - Mr. Michael Williams

- 32-years-old

- Heterosexual/Homosexual male

- Job: Engineer for a power company

- Length of time at job: 9 years

- Active in his church.

- No prior arrests.

- No history of being violent.
The Defendant - Mr. Charles Johnson

- 35-years-old

- Heterosexual male

- Job: Engineer for a gas company

- Length of time at job: 12 years

- Active in his church.

- No prior arrests.

- No history of being violent.

Events of the crime: 1:25 a.m. on Friday, September 18, 2006

1. Mr. Williams was leaving a bar frequented by gay men. He crossed the street to go to his car and was confronted by Mr. Johnson.

2. Mr. Johnson asked Mr. Williams, "Did you just leave that faggot bar?"

3. Mr. Williams ignored the question and kept walking.

4. Mr. Johnson pushed Mr. Williams to the ground and hit him a number of times.

5. While hitting Mr. Williams, Mr. Johnson cursed at him. He also called him a "faggot" and a "queer."

6. Mr. Johnson then pulled out a knife and stabbed Mr. Williams four times in the stomach.

7. A witness called the police. Mr. Williams was taken to the hospital. He had several surgeries to repair damage from the stab wounds. He remained in the hospital for three weeks.

8. Mr. Johnson was arrested the day after the attack and taken to the police station.

9. In a video line-up, Mr. Williams identified Mr. Johnson as the man who attacked him.

Information from the trial:

- A neighbor of Mr. Johnson testified that Mr. Johnson often complained about gay people. This neighbor also stated that Mr. Johnson bragged about what he did after he returned home that night. He added that Mr. Johnson told him that "the fag deserved what he got." 


\section{APPENDIX E}

\section{SRF}

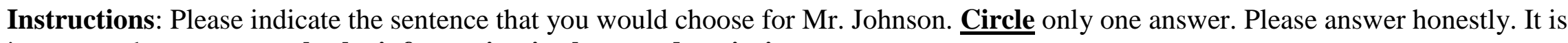
important that you use only the information in the case description.

$\begin{array}{lllllll}\text { No Punishment } & \text { Probation } & 1 \text { month } & 3 \text { months } & 6 \text { months } & 12 \text { months } & 3 \text { years } \\ 5 \text { years } & 7 \text { years } & 10 \text { years } & 15 \text { years } & 20 \text { years } & 30 \text { years } & \text { Life }\end{array}$




\section{APPENDIX F}

\section{PPBS}

Instructions: Please rate the defendant on the following qualities. Please circle a number for each item even if you find it difficult to rate the individual on each item.

\begin{tabular}{|c|c|c|c|c|c|c|c|}
\hline Example: Rude & $\begin{array}{l}1 \quad 2 \\
1=\text { You } \\
4=\text { You } \\
7=\text { You }\end{array}$ & $\begin{array}{l}3 \\
\text { ie } \\
\text { ie } \\
\text { ie }\end{array}$ & $\begin{array}{l}4 \\
\text { ne c }\end{array}$ & $\begin{array}{l}5 \\
\text { end } \\
\text { end }\end{array}$ & $\begin{array}{l}\text { is } \\
\text { is }\end{array}$ & $\begin{array}{l}7 \\
y \mathrm{r} \\
\text { all } \\
\text { y p }\end{array}$ & olite \\
\hline Violent & 1 & 3 & 4 & 5 & 6 & 7 & Non violent \\
\hline Gentle & 1 & 3 & 4 & 5 & 6 & 7 & Forceful \\
\hline Insane & 1 & 3 & 4 & 5 & 6 & 7 & Sane \\
\hline Good Natured & 1 & 3 & 4 & 5 & 6 & 7 & Vicious \\
\hline Mean & 1 & 3 & 4 & 5 & 6 & 7 & Kind \\
\hline $\begin{array}{l}\text { Blameless } \\
\text { (in general) }\end{array}$ & 1 & 3 & 4 & 5 & 6 & 7 & Blameworthy \\
\hline Fault & 1 & 3 & 4 & 5 & 6 & 7 & Faultless \\
\hline Harmful & 1 & 3 & 4 & 5 & 6 & 7 & Harmless \\
\hline Hurtful & 1 & 3 & 4 & 5 & 6 & 7 & Not hurtful \\
\hline $\begin{array}{l}\text { Responsible } \\
\text { (in general) }\end{array}$ & 1 & 3 & 4 & 5 & 6 & 7 & Irresponsible \\
\hline Careful & 1 & 3 & 4 & 5 & 6 & 7 & Reckless \\
\hline Pays careful attention & 2 & 3 & 4 & 5 & 6 & 7 & Careless \\
\hline
\end{tabular}




$\begin{array}{lllllllll}\text { Reliable } & 1 & 2 & 3 & 4 & 5 & 6 & 7 & \text { Unreliable } \\ \text { Dependable } & 1 & 2 & 3 & 4 & 5 & 6 & 7 & \text { Undependable }\end{array}$




\section{APPENDIX G}

\section{PVBS}

Instructions: Please rate the victim on the following qualities. Please circle a number for each item even if you find it difficult to rate the individual on each item.

\begin{tabular}{|c|c|c|c|c|c|c|c|}
\hline Example: Rude & $\begin{array}{l}1 \quad 2 \\
1=\text { You } \\
4=\text { You } \\
7=\text { You }\end{array}$ & $\begin{array}{l}3 \\
\text { ie } \\
\text { ie } \\
\text { ie }\end{array}$ & 4 & $\operatorname{im}$ & $\begin{array}{l}6 \\
\text { er }\end{array}$ & $\begin{array}{l}7 \\
\text { de } \\
\text { ru } \\
\text { lit }\end{array}$ & \\
\hline Violent & 1 & 3 & 4 & 5 & 6 & 7 & Non violent \\
\hline Gentle & 1 & 3 & 4 & 5 & 6 & 7 & Forceful \\
\hline Insane & 1 & 3 & 4 & 5 & 6 & 7 & Sane \\
\hline Good Natured & 1 & 3 & 4 & 5 & 6 & 7 & Vicious \\
\hline Mean & 1 & 3 & 4 & 5 & 6 & 7 & Kind \\
\hline $\begin{array}{l}\text { Blameless } \\
\text { (in general) }\end{array}$ & 1 & 3 & 4 & 5 & 6 & 7 & Blameworthy \\
\hline Fault & 1 & 3 & 4 & 5 & 6 & 7 & Faultless \\
\hline Harmful & 1 & 3 & 4 & 5 & 6 & 7 & Harmless \\
\hline Hurtful & 1 & 3 & 4 & 5 & 6 & 7 & Not hurtful \\
\hline $\begin{array}{l}\text { Responsible } \\
\text { (in general) }\end{array}$ & 1 & 3 & 4 & 5 & 6 & 7 & Irresponsible \\
\hline Careful & 1 & 3 & 4 & 5 & 6 & 7 & Reckless \\
\hline Pays careful attention & 2 & 3 & 4 & 5 & 6 & 7 & Careless \\
\hline
\end{tabular}




$\begin{array}{lllllllll}\text { Reliable } & 1 & 2 & 3 & 4 & 5 & 6 & 7 & \text { Unreliable } \\ \text { Dependable } & 1 & 2 & 3 & 4 & 5 & 6 & 7 & \text { Undependable }\end{array}$




\section{APPENDIX H}

\section{MHS}

Instructions: Please rate the statements below on the following 5-point scale. Place your answers to the left of the item number.

$1=$ "strongly disagree"

$2=$ "disagree"

$3=$ "don't know"

$4=$ "agree"

$5=$ "strongly agree"

1. Many gay men use their sexual orientation so that they can obtain special privileges.

2. Gay men seem to focus on the ways in which they differ from heterosexuals, and ignore the ways in which they are the same.

3. Gay men do not have all the rights they need.

4. The notion of universities providing students with undergraduate degrees in Gay and Lesbian Studies is ridiculous.

5. Celebrations such as "Gay Pride Day" are ridiculous because they assume that an individual's sexual orientation should constitute a source of pride.

6. Gay men still need to protest for equal rights.

7. Gay men should stop shoving their lifestyle down other people's throats.

8. If gay men want to be treated like everyone else, then they need to stop making such a fuss about their sexuality/culture.

9. Gay men who are "out of the closet" should be admired for their courage.

10. Gay men should stop complaining about the way they are treated in society, and simply get on with their lives.

11. In today's tough economic times, American tax dollars shouldn't be used to support gay men's organizations.

12. Gay men have become far too confrontational in their demand for equal rights. 


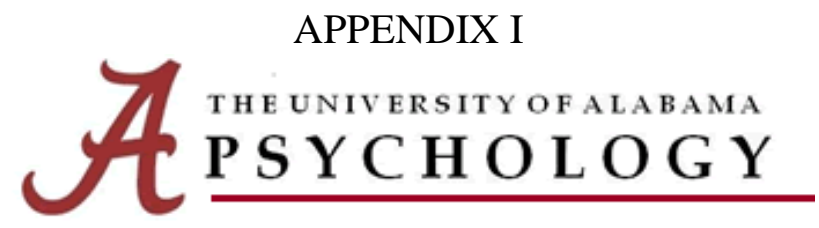

\section{Feedback Questionnaire}

Directions: Your opinion is very helpful for us as we attempt to improve our study. We would like to know what you liked and disliked about the activities you completed today. Please think back to all of the activities you completed with the research assistant today, and answer the following questions.

1) Were there any part(s) of the questionnaires you completed today that were unclear?

$\square$ No

$\square$ Yes. If yes, please explain below.

2) Were there any part(s) of the questionnaires that made you uncomfortable?

No

$\square$ Yes. If yes, please describe below. 


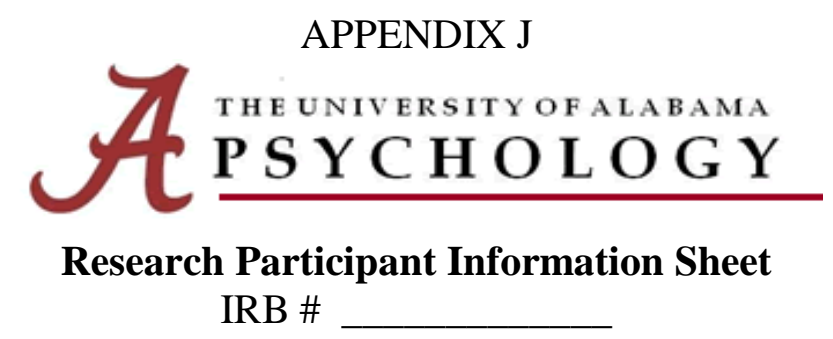

You are being asked to take part in a pilot study for a future research project. This study is called "Juror Perceptions." The study is being carried out by Erin Gorter who is a doctoral student at the University of Alabama. Ms. Gorter is being supervised by Dr. Karen Salekin, who is a licensed clinical psychologist and assistant professor at the University of Alabama.

\section{What is this study about?}

This study is being carried out to help determine the most appropriate questionnaires to use for a project that will examine how different elements of a trial impact a jurors' perception of the case.

\section{Why is this study important - What good will the results do?}

This pilot study will help to provide support for the implementation of a larger project. The knowledge from the larger project will help psychologists understand how jurors make decisions regarding sentences in criminal trials.

\section{Why have I been asked to take part in this study?}

You are currently a student at The University of Alabama taking part in an undergraduate psychology course.

\section{How many people besides me will be in this study?}

About 30 people will be in the pilot study phase of this project. Approximately 150 people will be involved in the subsequent study.

\section{What will I be asked to do in this study?}

If you decide to be in this study, you will be asked to do these things:

1. Fill out a sheet of paper with some general information about yourself (no name required).

2. Read a case description.

3. Fill out three short questionnaires related to the case description.

4. Fill out one questionnaire about your general views of people.

\section{How much time will I spend being in this study?}

This study will take about 20 to 30 minutes to complete.

\section{Will being in this study cost me anything?}

There will be no cost to you except for your time in completing the questionnaires. 
What are the benefits (good things) that may happen to me if I am in this study?

You will receive a research credit of 0.5 in your undergraduate psychology course. Although other benefits cannot be promised in research, it is possible that you will learn more about your attitudes toward the situations included in this study.

\section{What are the benefits to scientists or society?}

This study will help psychologists learn more about how people involved on juries make decisions about blame and sentences in criminal trials. This information can help make sure individuals on trial and victims of a crime are judged fairly.

\section{What are the risks (dangers or harm) to me if I am in this study?}

It is possible that you may feel some discomfort when answering questions included in the questionnaires. You can refuse to answer any questions that you think are too personal or upsetting. You can also stop participating in the study at any time without consequence.

\section{How will my confidentiality (privacy) be protected? What will happen to the information the study keeps on me? \\ The only identifying information you will be asked to provide will be signing this consent form. The consent form will be stored in a locked cabinet that can only be accessed by the investigators. The consent form and questionnaires will be stored separately.}

\section{What are my rights as a participant?}

Taking part in this study is voluntary - it is your free choice. You may choose not to take part at all. If you start the study, you can stop at any time. Leaving the study will not result in any penalty or loss of any benefits you would otherwise receive.

The University of Alabama Institutional Review Board (IRB) is the committee that protects the rights of people in research studies. The IRB may review study records from time to time to be sure that people in research studies are being treated fairly and that the study is being carried out as planned.

\section{Who do I call if I have questions or problems?}

If you have questions about the study right now, please ask them. If you have questions about the study later on, please call or email the investigator, Erin Gorter, at (602) 561-5776 or elgorter@bama.ua.edu. You can also call or email her faculty supervisor, Dr. Karen Salekin, at (205) 348-0679 or ksalekin@bama.ua.edu. If you have any questions about your rights as a research participant you may contact Ms. Tanta Myles, the University of Alabama Research Compliance Officer, at (205) 348-5152.

My signature confirms that I have read this participant information sheet. The study has been explained to me. I understand what I will be asked to do. I freely agree to take part in this study. I will receive a copy of this participant information sheet to keep. 
Signature of Research Participant

Investigator or Research Assistant
Date

Date 


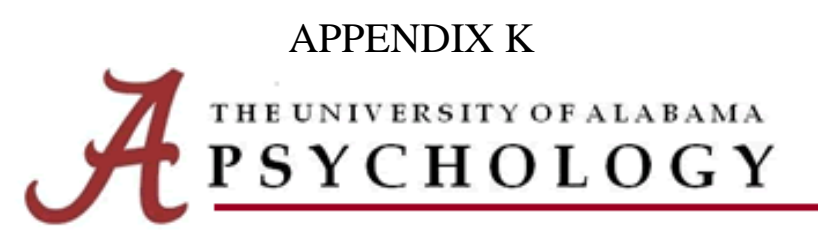

\section{Debriefing Form}

To the participant,

The goals of the current study are listed below:

1. To explore what impacts sentencing choice in hate crimes as they become more severe.

2. To explore how more severe crimes and victim sexual orientation impact:

a. Juror perceptions of defendant blame.

b. Juror perceptions of victim blame.

c. Who jurors feel are at fault.

3. To explore the impact of jurors' beliefs on their views of hate crimes.

You may email or call the primary investigator, Erin Gorter, if you have any questions after this session. You can also contact her if you would like the results of this study. She will keep your contact information on file and send the results once data has been analyzed. After the results have been sent to you, your contact information will be shredded.

Email: elgorter@bama.ua.edu

Phone: (602) 561-5776

You may also contact the faculty supervisor, Karen Salekin, Ph.D. She is a licensed clinical psychologist and assistant professor. She is available if you have questions about any part of this study.

Email: ksalekin @bama.ua.edu

Phone: (205) 348-0679

If you have any questions/concerns about your rights as a research participant, please contact Ms. Tanta Myles, Research Compliance Officer, at (205) 348-5152.

Thank you for taking the time to participate in this study.

Sincerely,

Erin L. Gorter

Department of Psychology

The University of Alabama

Gordon Palmer Hall

elgorter@bama.ua.edu

(602) $561-5776$ 


\section{APPENDIX L}

AFS

Instructions: Please indicate who you believe is at fault in this case. Circle your answer on a scale of 1 to 7, 1 being "Entirely Mr. Williams' fault" and 7 being "Entirely Mr. Johnson's fault." Please answer honestly. It is important that you use only the information in the case description. 


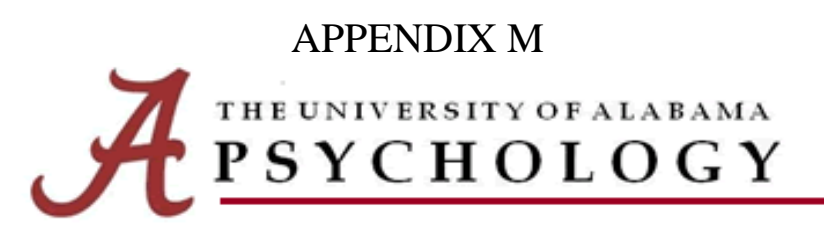

Research Informed Consent Form

IRB \#

You are being asked to take part in a research study called "Juror Perceptions." The study is being carried out by Erin Gorter who is a doctoral student at the University of Alabama. Ms. Gorter is being supervised by Dr. Karen Salekin, who is a licensed clinical psychologist and assistant professor at the University of Alabama.

This study is being paid for by the American Academy of Forensic Psychology (AAFP) and the American Psychological Association of Graduate Students.

What is this study about?

This study is being carried out to examine how different elements of a trial impact a jurors' perception of the case.

Why is this study important - What good will the results do?

The knowledge from this study will help psychologists understand how jurors make decisions regarding sentences in criminal trials.

Why have I been asked to take part in this study?

You have been asked to be in this study because you are eligible for jury selection and were recently selected to be part of a jury pool in the state of Alabama.

How many people besides me will be in this study?

Approximately 150 people will be in this study.

What will I be asked to do in this study?

If you decide to be in this study, you will be asked to do these things:

5. Fill out a sheet of paper with some general information about yourself (no name required).

6. Read a case description.

7. Fill out three short questionnaires related to the case description.

8. Fill out one questionnaire about your general views of people.

How much time will I spend being in this study?

This study will take about 20 to 30 minutes to complete.

Will I be paid for being in this study?

If you complete the entire study, you will be paid $\$ 10$ for your time. 
Will being in this study cost me anything?

There will be no cost to you except for your time in completing the questionnaires.

What are the benefits (good things) that may happen to me if I am in this study?

Although benefits cannot be promised in research, it is possible that you will learn more about your attitudes toward the situations included in this study.

\section{What are the benefits to scientists or society?}

This study will help psychologists learn more about how people involved on juries make decisions about blame and sentences in criminal trials. This information can help make sure individuals on trial and victims of a crime are judged fairly.

\section{What are the risks (dangers or harm) to me if I am in this study?}

It is possible that you may feel some discomfort when answering questions included in the questionnaires. You can refuse to answer any questions that you think are too personal or upsetting. You can also stop participating in the study at any time without consequence.

\section{How will my confidentiality (privacy) be protected? What will happen to the information the study keeps on me?}

The only identifying information you will be asked to provide will be signing this consent form. The consent form will be stored in a locked cabinet that can only be accessed by the investigators. The consent form and questionnaires will be stored separately. All consent forms will be destroyed upon completion of the study.

\section{What are my rights as a participant?}

Taking part in this study is voluntary - it is your free choice. You may choose not to take part at all. If you start the study, you can stop at any time. Leaving the study will not result in any penalty or loss of any benefits you would otherwise receive.

The University of Alabama Institutional Review Board (IRB) is the committee that protects the rights of people in research studies. The IRB may review study records from time to time to be sure that people in research studies are being treated fairly and that the study is being carried out as planned.

\section{Who do I call if I have questions or problems?}

If you have questions about the study right now, please ask them. If you have questions about the study later on, please call or email the investigator, Erin Gorter, at (602) 561-5776 or elgorter@bama.ua.edu. You can also call or email her faculty supervisor, Dr. Karen Salekin, at (205) 348-0679 or ksalekin@bama.ua.edu. If you have any questions about your rights as a research participant you may contact Ms. Tanta Myles, the University of Alabama Research Compliance Officer, at (205) 348-5152.

My signature confirms that I have read this consent form. The study has been explained to me. I understand what I will be asked to do. I freely agree to take part in this study. I will receive a copy of this consent form to keep. 
Signature of Research Participant

Investigator or Research Assistant
Date

Date 


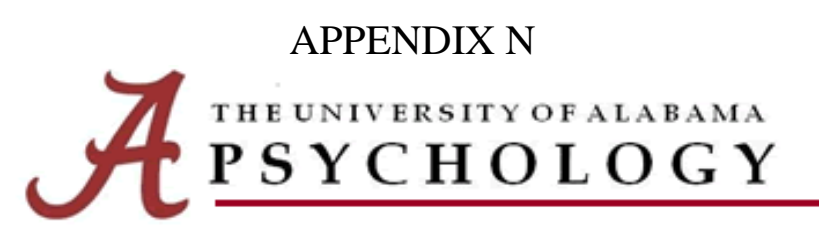

Debriefing/Second Consent Form

To the participant,

The goals of the current study are listed below:

4. To find out how jurors decide on a sentence for perpetrators of hate crimes. Does the victim's sexual orientation or a juror's beliefs change the length of sentence they give the perpetrator?

5. To see if more severe crimes and the victim's sexual orientation change how much jurors:

a. Blame the perpetrator.

b. Blame the victim.

6. To find out if a juror's beliefs impacts their views of hate crimes. Do people with more negative views of homosexuality blame the perpetrator/victim more or less?

The full purpose of this study was not provided in the first consent form to ensure that what you were told about the study did not impact how you responded. If you have any questions or concerns about this, please let me know immediately.

You may email or call the primary investigator, Erin Gorter, if you have any questions after this session (email: elgorter@ bama.ua.edu; phone: 602-561-5776). If you would like to know the results of this study, please let her know and she will get your contact information. She will keep your contact information on file and send you the results once the study is finished. After the results have been sent to you, your contact information will be shredded.

You can also email or call her supervisor, Karen Salekin, Ph.D. She is a licensed clinical psychologist and assistant professor. She is available if you have questions about any part of this study (email: ksalekin@bama.ua.edu; phone: 205-348-0679).

Finally, you can also call Ms. Tanta Myles, Research Compliance Officer, at 205-348-5152. She can answer any questions or concerns about your rights as a research participant.

Now that you know the full purpose of this study, please sign the line below indicating whether you are still willing to allow your data to be included in this study.

Yes. I will allow my data to be used in this study. (sign below)

No. I do not want my data used. Please destroy it immediately. (sign below) 